\title{
可见光催化在有机合成中的应用
}

\author{
戴小军许孝良*李小年* \\ (浙江工业大学工业催化研究所 绿色化学合成技术国家重点实验室培育基地 杭州 310014)
}

\begin{abstract}
摘要 可见光催化具有成本低、易获得和环境友好等特点，近几年在有机合成中得到了广泛应用，并成为其中增长最 快的领域之一. 主要综述了近年来可见光催化在有机合成中的发展和应用, 并对其发展进行了展望.

关键词 可见光催化; 绿色化学; 有机合成
\end{abstract}

\section{Applications of Visible Light Photoredox Catalysis in Organic Synthesis}

\author{
Dai, Xiaojun $\quad \mathrm{Xu}$, Xiaoliang* ${ }^{*} \mathrm{Li}$, Xiaonian* \\ (State Key Laboratory Breeding Base of Green Chemistry Synthesis Technology, Industrial Catalysis Institute, \\ Zhejiang University of Technology, Hangzhou 310014)
}

\begin{abstract}
Recently visible light photoredox catalysis was widely used in organic synthesis. Due to its low cost, easy availability and environmental friendliness, it has become one of the fastest growing fields in organic chemistry. This review summarizes recent development and application of visible light photoredox catalysis in organic synthesis and also gave its outlook in the future.

Keywords visible light photoredox catalysis; green chemistry; organic synthesis
\end{abstract}

可见光具有天然丰度大、使用简单、应用潜力巨大， 具有绿色化的特点, 使得可见光催化成为有机合成的一 种强大手段, 从 19 世纪初就受到了化学家的关注 ${ }^{[1]}$. 自 19 世纪 70 年代, 可见光催化才逐渐地运用到有机合成 中, 并开始被人们所关注. 但是直到最近几年可见光催 化在该领域才有了巨大的突破, 成为一个热门的研究领 域，真正发展成为有机合成的一种实用方法 ${ }^{[2 ~ 10]}$.
可见光催化剂主要可分为金属络合物和大分子共 轭物质两大类. 其中金属络合物主要有 $\mathrm{Ru}(\mathrm{II}), \operatorname{Ir}(\mathrm{III})$ 与 有机小分子的络合物, 如 $\left[\mathrm{Ru}(\mathrm{bpy})_{3}\right] \mathrm{Cl}_{2},\left[\operatorname{Ir}(\mathrm{ppy})_{2}(\mathrm{dtb}-\right.$ $\mathrm{bpy})]^{+}\left(\mathrm{PF}_{6}^{-}\right)$等. 大分子共轭物质主要是一些感光的天 然色素和染料, 如 eosin Y, rose bengal ${ }^{[6]}$ (Scheme 1).

根据催化剂的历程不同, 可见光催化反应可分为氧 化淬灭循环和还原淬灭循环. 以金属络合物 $\left[\mathrm{Ru}(\mathrm{bpy})_{3}\right]-$

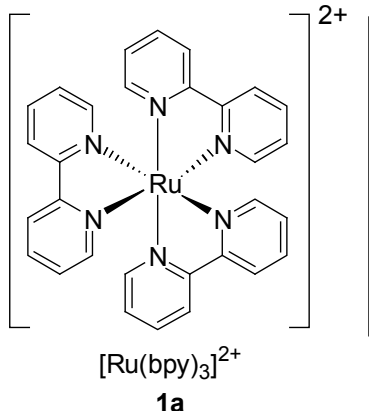

1a

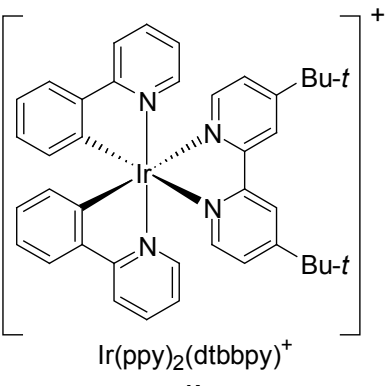

$1 \mathrm{~b}$<smiles>O=C(O)c1ccccc1-c1c2cc(Br)c(=O)c(Br)c-2oc2c(Br)c(O)c(Br)cc12</smiles>

$\operatorname{eosin} \mathrm{Y}$ 1c<smiles>NC(=O)c1c(Cl)c(Cl)c(Cl)c(Cl)c1-c1c2cc(I)c(=O)c(I)c-2oc2c(I)c(O[18O])c(I)c([N+](=O)[O-])c12</smiles>

$1 d$

Scheme 1

\footnotetext{
*E-mail: xuxiaoliang@zjut.edu.cn; xnli@zjut.edu.cn

Received April 18, 2013; revised May 9, 2013; published online May 24, 2013.

Project supported by the National Basic Research Program of China (973 Program, No. 2011CB710800) and the Zhejiang Provincial Natural Science Foundation of China (No. LY12B02017).

国家重点基础研究发展计划(973 计划, No. 2011CB710800)和浙江省自然科学基金(No. LY12B02017)资助项目.
} 
$\mathrm{Cl}_{2}$ 为例, $\mathrm{Ru}(\mathrm{bpy})_{3}^{2+}$ 在可见光照射下转变为 $\mathrm{Ru}(\mathrm{bpy}){ }_{3}^{2+*}$, 若进一步被氧化成 $\mathrm{Ru}(\mathrm{bpy})_{3}^{3+}$ 则为氧化淬灭, 而被还原 成 $\mathrm{Ru}(\mathrm{bpy})_{3}^{+}$为还原淬灭 ${ }^{[3]}$ (Scheme 2). 图中 A (electron-acceptor)为电子受体, 如重氮盐、硝基化合物、卤 化物、甲基紫罗碱、过硫酸盐和 $\mathrm{O}_{2}$ 等, 都可作为氧化淬 灭试剂; 而 $\mathrm{D}$ (electron-donor) 为电子供体, 如胺类、 Hantzsch 酯和 EDTA 等, 可作为还原淬灭试剂.

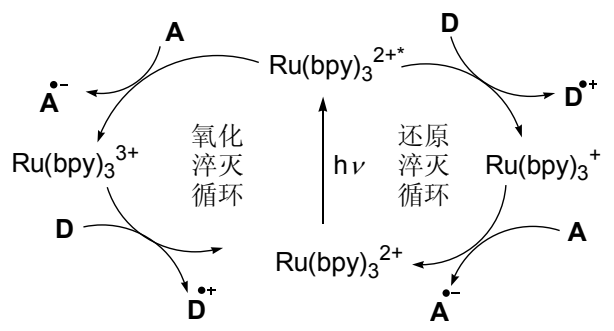

Scheme 2

本文主要根据底物及反应类型的不同, 对近几年来 可见光催化剂在有机合成中的应用进行了综述.

\section{1 醛酮羰基 $\alpha$ 位的取代反应}

有机化学中, 羰基化合物主要包括醛、酮、酯和酰 胺等. 醛、酮羰基的 $\alpha$ 位比较活泼, 容易进行各种取代 反应. MacMillan 等 ${ }^{[11]}$ 首次用可见光催化实现醛 $\alpha$ 位的 烷基化反应，同时这也是一种构建手性碳的有效方法， 属于光催化领域里不对称催化的一个重要组成部分.

2008 年 MacMillan 等 ${ }^{[11]}$ 报道了用 $\left[\mathrm{Ru}(\mathrm{bpy})_{3}\right] \mathrm{Cl}_{2}$ 作光 催化剂, 手性咪唑酮类化合物 4 作有机催化剂, 在光照 条件下实现了对醛的 $\alpha$-烷基化(Eq. 1). 该反应具有广泛 的应用性, 并具有高对应选择性和操作简单的特点, 这 对醛的不对称烷基化具有重要意义.

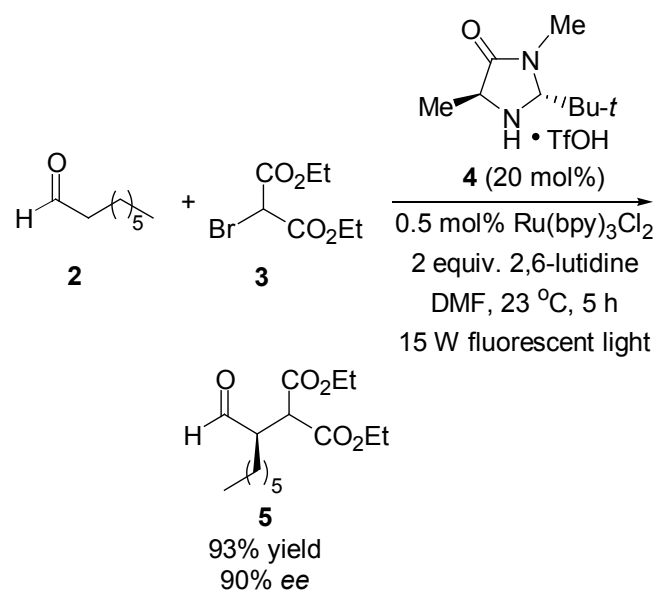

随后 2009 年, MacMillan 等 ${ }^{[12]}$ 将这一方法运用于对 醛的 $\alpha$-三氟甲基化和全氟烷基化, 取得了不错的收率和 $e e$ 值(Eq. 2). 研究表明铱催化剂的催化效果要比钓催化 剂好, 能得到更高的收率和高 $e e$ 值.

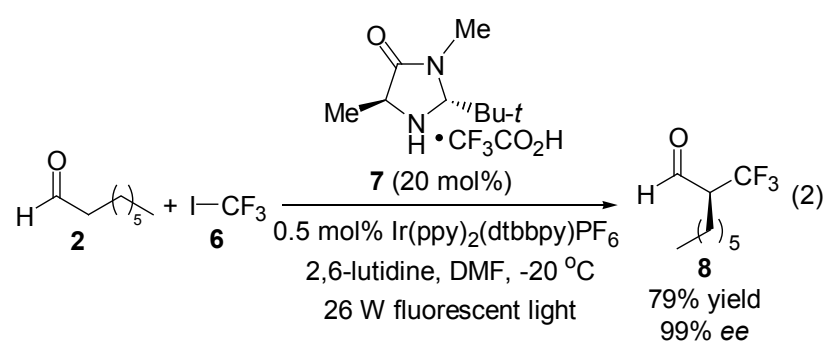

MacMillan 等 ${ }^{[13]}$ 又用缺电子的芳烃和杂芳烃完成了 对醛的 $\alpha$-苠基化(Eq. 3). 同样用铱催化剂的催化效果要 比钓催化剂好. 该方法可用于合成一种血管增生抑制剂 类药物, 对糖尿病、视网膜病和肿瘤增生等有一定治疗 作用.

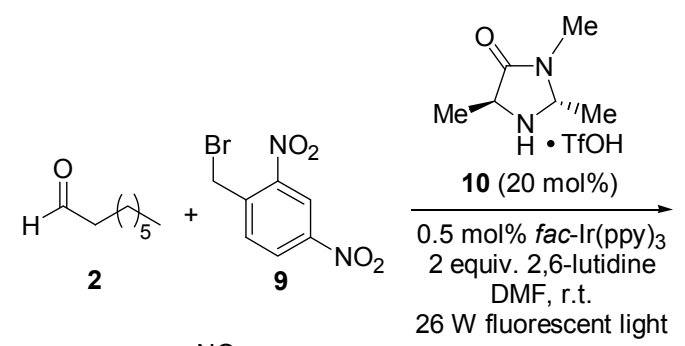<smiles>CCCC(C)C(C=O)Cc1ccc([N+](=O)[O-])cc1[N+](=O)[O-]</smiles>

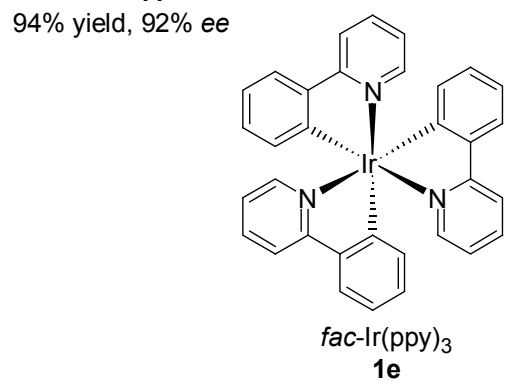

Zeitler 等 ${ }^{[14]}$ 继续研究了对醛的不对称 $\alpha$-烷基化和全 氟烷基化(Eq. 4). 他们利用有机染料 eosin Y 代替金属催 化剂作光催化剂, 结合手性咪唑酮类化合物 $\mathbf{4}$, 取得了 相似结果.

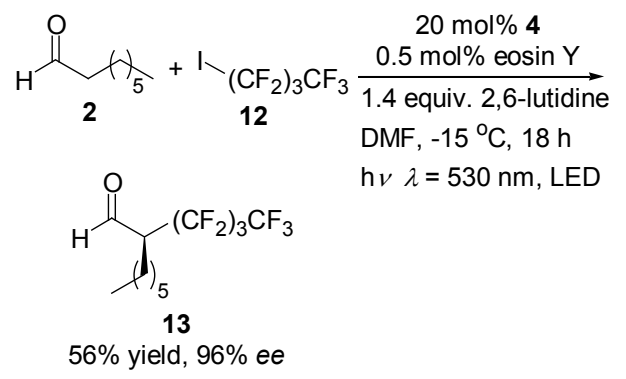

MacMillan 等 ${ }^{[15]}$ 把底物从醛拓展到各种酮、酯和酰 
胺. 先通过与卤代硅烷反应得到烯醇硅烷，再利用光催 化剂和有机催化剂共同作用下，在一个温和的条件下完 成了对酮的 $\alpha$-三氟甲基化(Eq. 5).

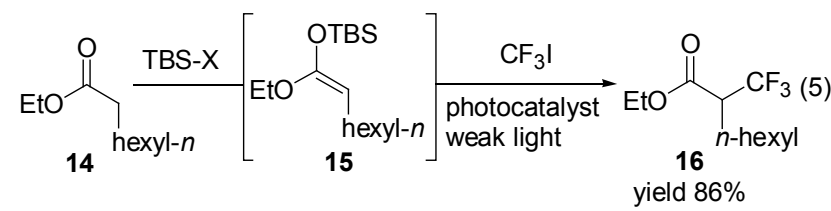

König 等 ${ }^{[16]}$ 报道了用无机金属氧化物作光催化剂, 结合手性咪唑酮类化合物作有机催化剂, 在光照条件下 实现了对醛的 $\alpha$-烷基化(Eq. 6).

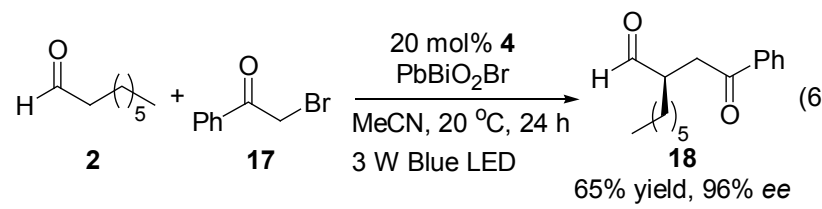

2009 年 Akita 等 ${ }^{[17]}$ 报道了在光催化剂存在条件下, 能够实现醛的 $\alpha$-差氨基化(Eq. 7).

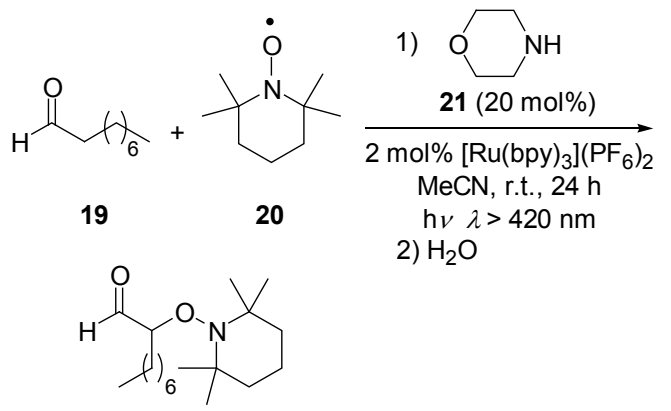

\section{2 环加成}

2008 年 Yoon 等 ${ }^{[18]}$ 首次用可见光催化的方法在 Lewis 酸存在条件下实现分子内的烯酮 $[2+2]$ 环加成 (Eq. 8).
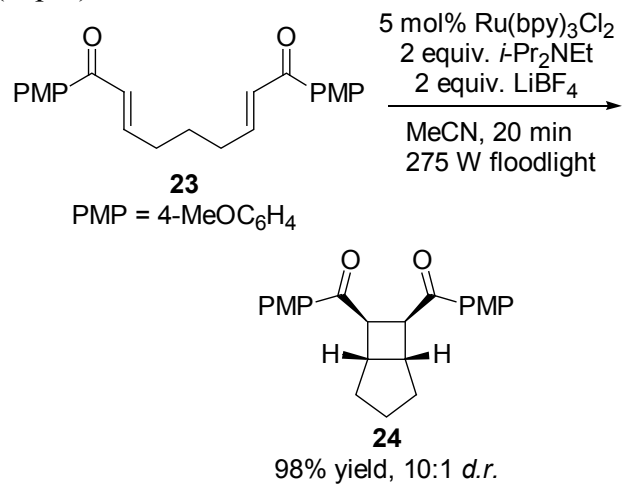

随后，他们 ${ }^{[19]}$ 又继续研究并尝试了分子间的烯酮
$[2+2]$ 环加成. 在 2009 年，完成对两种不同烯酮的 $[2+$ 2]环加成, 取得了不错的收率, 并有较好的对应选择性 (Eq. 9).

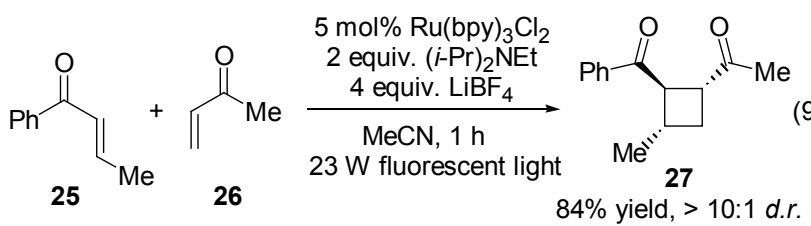

2010 年, 他们 ${ }^{[20]}$ 又尝试了对富电子烯烃的 $[2+2]^{2}$ 环 加成(Eq. 10). 其中甲基紫罗碱作为原始的氧化剂, 把 $\left[\mathrm{Ru}(\mathrm{bpy})_{3}\right]^{2+*}$ 氧化成 $\left[\mathrm{Ru}(\mathrm{bpy})_{3}\right]^{3+}$ ，故该反应机理为氧化 淬灭机理.

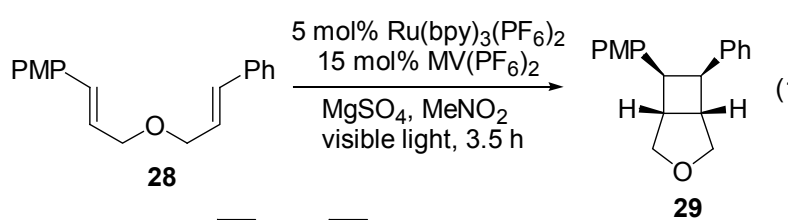

$89 \%$ yield, $>10: 1$ d.r.

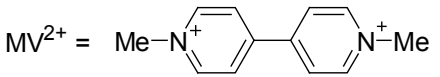

2011 年, Yoon 等 ${ }^{[21]}$ 突破原有的用 Lewis 酸催化, 改 用 Brønsted 酸, 得到了不同的实验结果(Eq. 11).

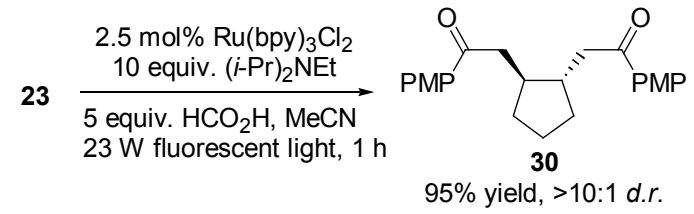

2011 年, Yoon 等 ${ }^{[22]}$ 研究了光催化在分子内有杂原 子参与的 Diels-Alder 反应中的应用(Eq. 12). 用钉催化 剂, 胺作为还原剂, 在 Lewis 酸存在条件下, 经光照实 现了分子内烯酮的 $[4+2]$ 环加成，并在该反应中取得很 好的非对映选择性和区域选择性. 反应得到的产物二氢 吡喃在有机合成反应中具有重要的转换作用.

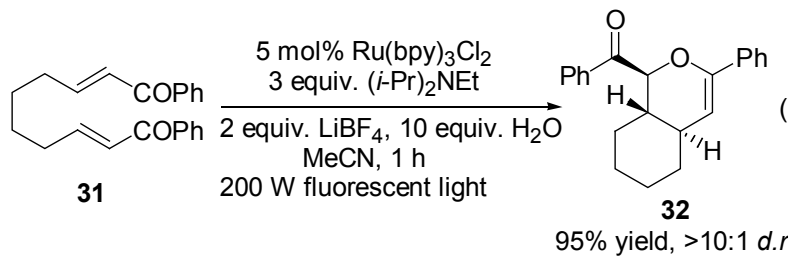

2011 年, Yoon 等 ${ }^{[23]}$ 用可见光催化实现了芳基环肉 基䣱对烯烃的 $[3+2]$ 环加成(Eqs. 13，14)，这一发现为 $[3+2]$ 环加成提供了一种新的方法.

2012 年, Zheng 等 ${ }^{[24]}$ 报道了以 $\left[\mathrm{Ru}(\mathrm{bpz})_{3}\right]\left(\mathrm{PF}_{6}\right)_{2}$ 为光 催化剂, 在可见光照射下环丙基胺与烯烃的 [3+2]环加 成(Eq. 15). 该反应具有很好的官能团容忍性，且反应条 
<smiles>CCOC(=O)/C(C)=C/CCCC1CC1C(=O)c1ccccc1</smiles>

33

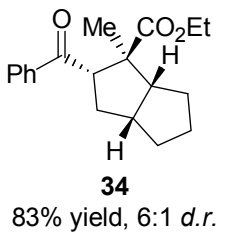

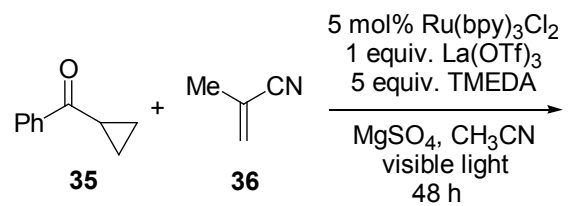<smiles>COC(=O)[C@H]1CCC[C@@]1(C)C#N</smiles>

37

$50 \%$ yield, $2: 1 \mathrm{~d} . r$.

1 equiv. $\mathrm{La}(\mathrm{OTf})_{3}$

$\underset{\mathrm{MgSO}_{4}, \mathrm{CH}_{3} \mathrm{CN}}{\stackrel{5}{\longrightarrow}}$

$$
6.5 \mathrm{~h}
$$

$2.5 \mathrm{~mol} \% \mathrm{Ru}(\mathrm{bpy})_{3} \mathrm{Cl}_{2}$

$23 \mathrm{~W}$ fluorescent light

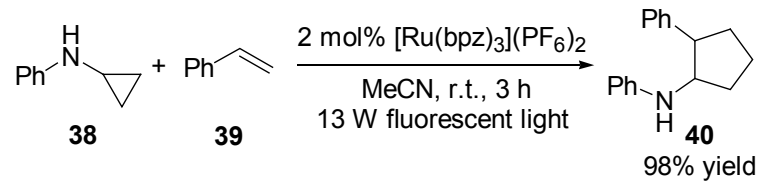

件温和、产率高. 这一发现也大大发展了可见光催化中 的 $[3+2]$ 环加成.

2011 年, Yoon 等 ${ }^{[25]}$ 又研究了分子间[4+2]环加成 (Eq. 16). 这打破了原有的 $[4+2]$ 环加成, 用光催化这一 新的技术使反应条件变得更温和, 也使得反应更符合绿 色化学的宗旨.

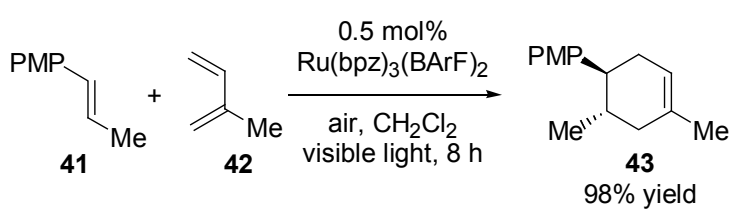

2012 年, Yoon 等 ${ }^{[26]}$ 在研究烯酮的[2+2]环加成时引 入了一个咪唑基团, 而环加成后可以用不同的亲核试剂 取代咪唑基团，得到多种结构不同的衍生物(Scheme 3).

2012 年, Yoon 等 ${ }^{[27]}$ 对双苯乙烯进行一个光催化氧 化, 实现了 $[2+2+2]$ 环加成, 并且得到一个含有 $1,2-$ 二 氧戊环的化合物 48 (Eq. 17). 这一反应的发现提供了一 种在分子中引入氧氧键的新方法, 对抗癌药物的研究制 备具有重要意义.

2012 年, Yoon 等 ${ }^{[28]}$ 继续研究了可见光催化分子内 Diels-Alder 反应(Eq. 18), 对该类型反应做了补充.

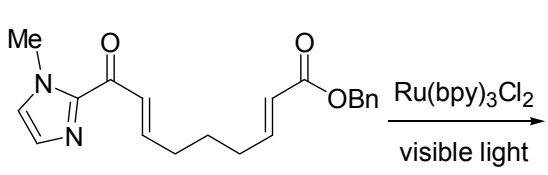

44

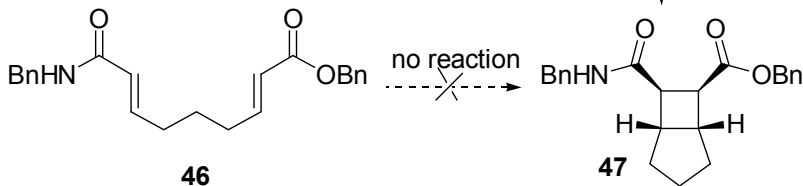

Scheme 3

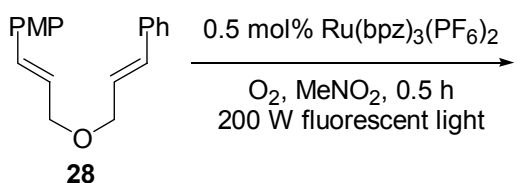<smiles></smiles>

$\left[\mathrm{Ru}(\mathrm{bpz})_{3}\right]^{2+}$

$1 f$<smiles>C/C=C\C=C\COC(=O)/C=C/[PH2+]</smiles>

49

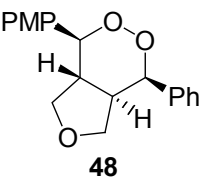

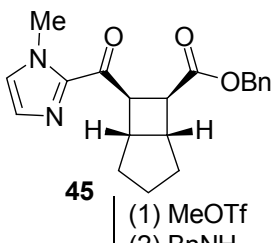

(2) $\mathrm{BnNH}_{2}$
2012 年, Xiao 等 ${ }^{[29]}$ 利用可见光催化对 3 位取代的氧 化吲哚 51 进行分子间的 $[2+2]$ 环加成, 得到一种具有两 个螺环的复杂化合物 52 (Eq. 19).

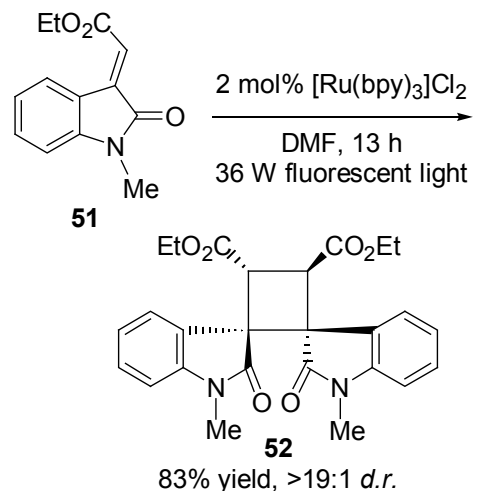

2012 年, Yoon 等 ${ }^{[30]}$ 继续研究了具有苯乙烯结构的 分子间的 $[2+2]$ 环加成, 得到一种非常简单可行且高效 
的方法(Eq. 20).
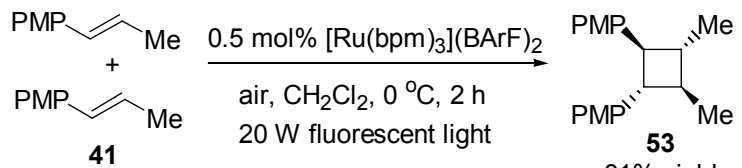

41

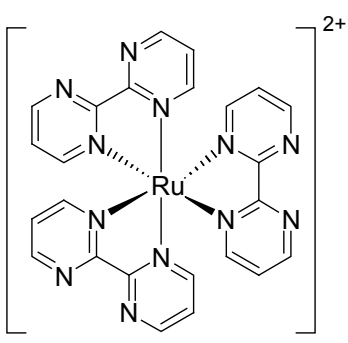

$81 \%$ yield

\section{3 含卤素化合物参与的反应}

\section{1 脱卤还原}

1985 年, Kellogg 等 ${ }^{[33]}$ 报道了 2-溴苯乙酮、澳代丙 二酸等带吸电子基团的卤代化合物的脱卤还原. 该反应 在光催化剂 $\left[\mathrm{Ru}(\mathrm{bpy})_{3}\right] \mathrm{Cl}_{2}$ 或二碘曙红催化下用 3-甲基2,3-二氢苯并噻唑类物质作还原剂, 光照条件下得到脱 卤还原产物，且产率很高(Scheme 4) ${ }^{[5]}$.

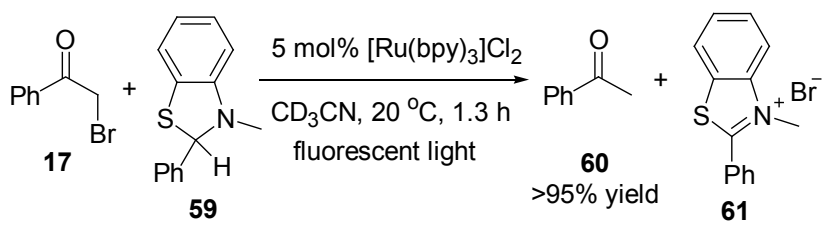

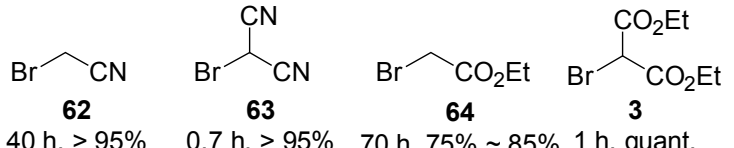<smiles>CC(=O)CCl</smiles>

65

60 h, $50 \%$<smiles></smiles>

66<smiles>CC(C)(C)S(=O)(=O)CBr</smiles>

67

\section{Scheme 4}

与 Kellogg 等不同, 1990 年 Fukuzumi 等 ${ }^{[34]}$ 改用二氢 听啶衍生物作为脱卤的还原剂, 并且还研究了高氯酸在 反应中的作用. 最后发现高氯酸的存在改变了反应机 理. 不加高氯酸时, 反应是通过还原猝灭, $\left[\mathrm{Ru}(\mathrm{bpy})_{3}\right]^{2+*}$ 与二氢呋啶衍生物作用生成还原剂 $\left[\mathrm{Ru}(\mathrm{bpy})_{3}\right]^{+}$. 然而当 有高氯酸存在时, 反应时通过氧化猝灭, $\left[\mathrm{Ru}(\mathrm{bpy})_{3}\right]^{2+*}$ 与 底物苯甲酰甲基卤化物作用生成氧化剂 $\left[R u(b p y)_{3}\right]^{3+}$ (Scheme 5).

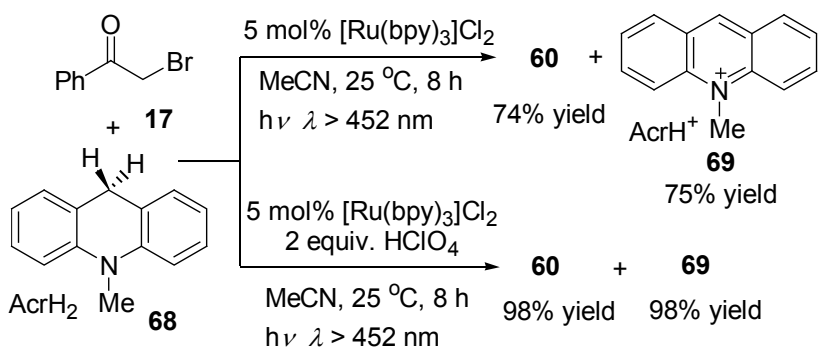

\section{Scheme 5}

2009 年, Stephenson 等 ${ }^{[35]}$ 报道了以 $\mathrm{Ru}(\mathrm{bpy})_{3} \mathrm{Cl}_{2}$ 作光 催化剂, 还原剂 $(i-\mathrm{Pr})_{2} \mathrm{NEt}$ 在甲酸或 Hantzsch 酯 71 的协 同作用下完成光催化脱卤还原反应(Eq. 23).

2010 年 Zeitler 等 ${ }^{[14]}$ 首次用廉价的有机染料作为光 催化剂, 完成了对羰基 $\alpha$ 位的脱卤还原(Eq. 24). 


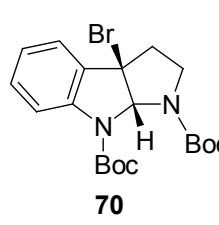

$2.5 \mathrm{~mol} \%\left[\mathrm{Ru}(\mathrm{bpy})_{3}\right] \mathrm{Cl}_{2}$

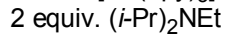

1.1 equiv. 71

10 equiv. $\mathrm{HCOOH}$

DMF, r.t., $4 \mathrm{~h}$

$14 \mathrm{~W}$ fluorescent light

$\mathrm{EtO}_{2} \mathrm{C}$

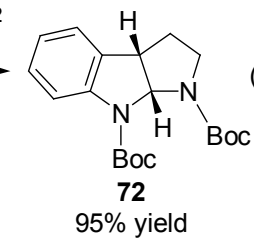

(23)

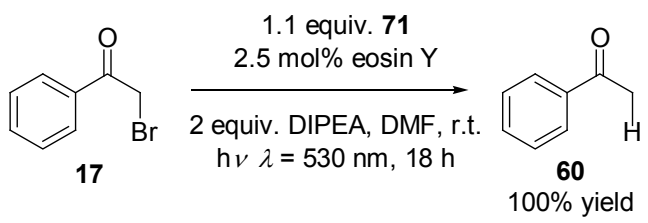

2011 年, Gagné 等 ${ }^{[36]}$ 研究了葡糖卤化物的光催化脱 卤还原. 用胺作为还原剂, 在钉催化剂存在条件下, 发 生光催化脱卤得自由基, 用硫醇作为氢源, 得到还原产 物(Scheme 6).
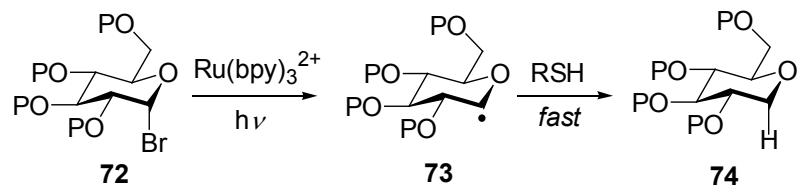

\section{Scheme 6}

2012 年, Stephenson 等 ${ }^{[37]}$ 报道了利用光催化对烷 基、烯基和芳基碘化物的脱卤还原(Eq. 25).
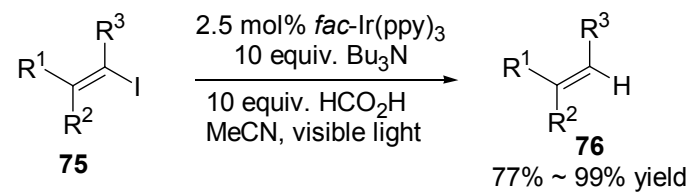

\section{2 脱卤加成}

2009 年, Stephenson 等 ${ }^{[38]}$ 报道了分子内对吲哚和吡 咯的自由基加成(Eq. 26). 他们利用 $\mathrm{Ru}(\mathrm{bpy})_{3} \mathrm{Cl}_{2}$ 作光催 化剂, 对底物 77 进行分子内的脱卤加成, 得到环状化合 物 78. 并且, 还研究得出了一种串联环化反应, 得到双 环化合物. 这一研究扩大了光催化在自由基反应领域的 应用, 是一种合成复杂分子的新途径.

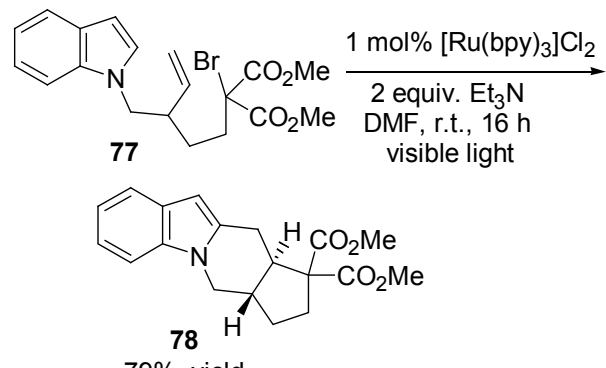

2010 年, Stephenson 等 $^{[39]}$ 又报道了一种分子内的自 由基环化反应(Eq. 27). 反应机理与之前报道的相似，但 是底物由原来富电子的吲哚和吡咯拓展为烯烃和炔烃, 大大拓宽了底物范围，使之更有应用价值. 同时还指出 在催化该类反应时, 铱催化剂的活性要高于钉催化剂, 前者往往能催化后者所不能催化的反应.<smiles>C#CCCCC(Br)C(=O)N1CCOC1=O</smiles>

79

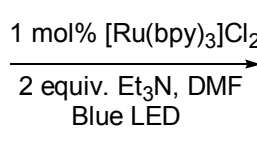

equiv. $\mathrm{Et}_{3} \mathrm{~N}, \mathrm{DMF}$
Blue LED<smiles>C=C1CCCC1C(=O)N1CCOC1=O</smiles>

$85 \%$ yield
随后，该研究小组 ${ }^{[40]}$ 在 2010 年报道了分子间卤代 烃对吲哚等富电子芳烃的自由基反应(Eq. 28).

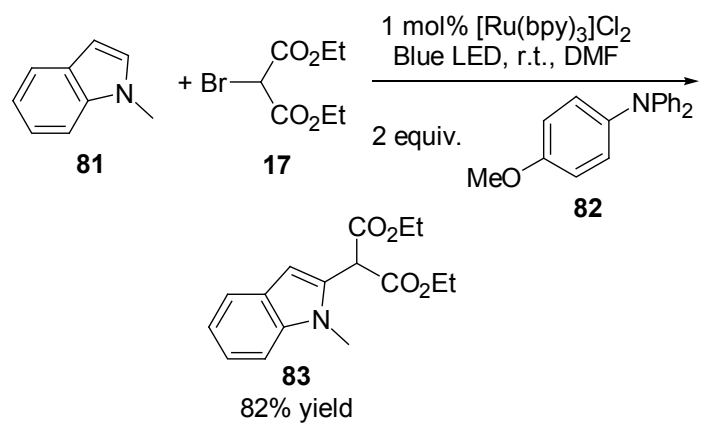

2011 年, Stephenson 等 ${ }^{[41]}$ 再次报道了利用光催化对 吲哚进行烷基化，并将其应用于对胶枝菌素 $\mathrm{C}$ 的合全成 (Eq. 29).<smiles>CC(=O)OC(=O)N1C(C(=O)OCc2ccccc2)CC2(Br)c3ccccc3N(C(=O)OCc3ccccc3)C12</smiles>

84

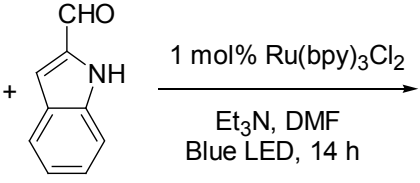

85<smiles>COC(=O)C1CC2(c3c(C=O)[nH]c4ccccc34)c3ccccc3N(C(=O)OC(C)(C)C)C2N1C(=O)OC(C)(C)C</smiles>

2010 年, Gagné 等 ${ }^{[42]}$ 报道了分子间的糖基卤化物和 缺电子烯烃的光催化加成反应(Eq. 30). 在室温下, 用钌 催化剂, 胺作还原剂, 成功得到加成产物.

2011 年, Stephenson 等 ${ }^{[43]}$ 再次利用光催化, 经过一 个串联的反应，完成了分子内溴代环丙烷与炔烃的加 成，其中苯基也参与了反应，最终得到一个多环的产物 91 (Eq. 31). 该反应的优点是在温和的反应条件下，用 一步简单反应完成了复杂环状化合物的合成. 

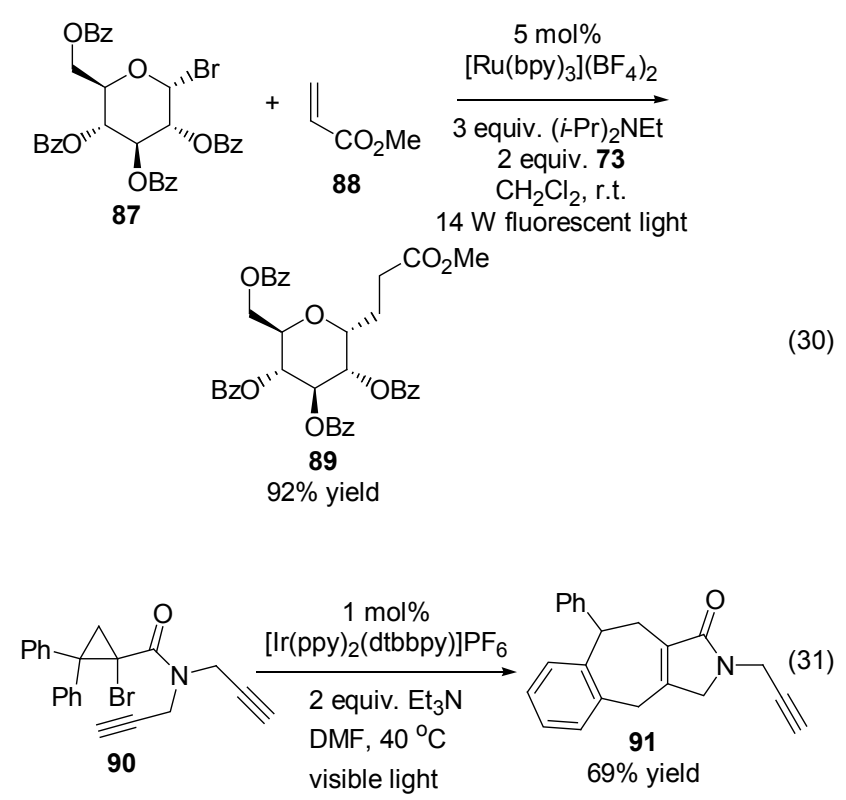

2012 年, $\mathrm{Yu}$ 等 ${ }^{[44}$ 报道了用铱作催化剂, 通过光催化 用 92 合成了 3,3-二取代的羰基吲哚 93(Eq. 32).<smiles>CC(=O)C(Br)(Br)C(=O)Nc1ccccc1</smiles>

$92 \mathrm{Me}$

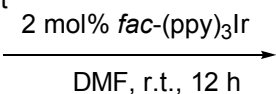

$40 \mathrm{~W}$ fluorescent light<smiles>CCOC(=O)C1(C)C(=O)N(C)c2ccccc21</smiles>

$93 \mathrm{Me}$
2012 年, Lee 等 ${ }^{[45]}$ 报道了用铱作催化剂, 催化了分 子内芳基卤化物与烯烃或炔烃的脱卤加成(Eq. 33). 至 此，底物已经不仅仅局限在带吸电子基团的烷基卤化 物.

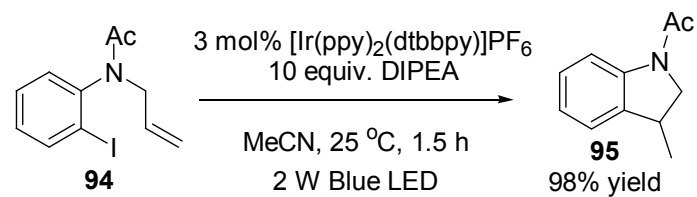

2013 年, Lei 等 ${ }^{[46]}$ 报道了用光催化完成对 $\alpha$-溴代羰 基化合物和茮基溴的链烯基化(Eq. 34).
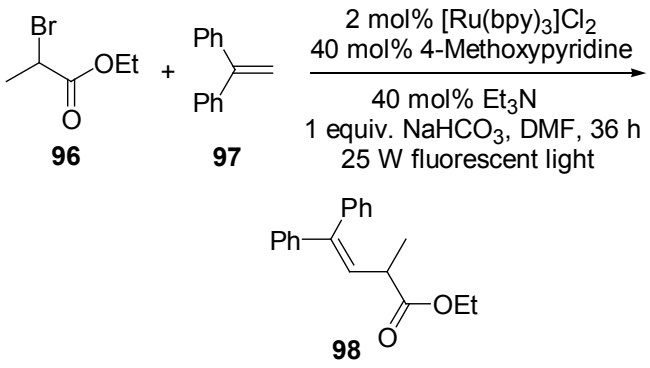

$72 \%$ yield 


\section{4 其它的一些涉卤反应}

Willner 等 ${ }^{[50,51]}$ 研究了一些关于有光还原剂 $\left[\mathrm{Ru}(\mathrm{bpy})_{3}\right]^{2+*}$ 参与的光催化反应. 根据他们对紫罗碱 $/ \mathrm{Na}_{2} \mathrm{~S}_{2} \mathrm{O}_{4}$ 还原体系在乙酸乙酯/水中的研究, 报道了由 $\left[\mathrm{Ru}(\mathrm{bpy})_{3}\right]^{2+}$ 和二正辛烷基紫罗碱 $\left(\mathrm{C}_{8} \mathrm{~V}^{2+}\right)$ 参与的 1,2-二 溴均二苯代已烯的脱溴的光催化反应(Eq. 39). 在乙酸 乙酯/水二相体系中紫罗碱阳离子自由基 $\mathrm{C}_{8} \mathrm{~V}^{+}$发生歧化 反应生成 $\mathrm{C}_{8} \mathrm{~V}^{0}, \mathrm{C}_{8} \mathrm{~V}^{0}$ 是这一脱溴过程中关键的还原剂. 与二相光催化脱溴不同, 酶催化的反应中引入了乙醇/ 乙醇脱氢酶/NADH 还原体系 ${ }^{[52]}$. 在这个过程中 $\mathrm{NADH}$ 代替了 EDTA 把 $\left[\mathrm{Ru}(\mathrm{bpy})_{3}\right]^{3+}$ 还原成 $\left[\mathrm{Ru}(\mathrm{bpy})_{3}\right]^{2+[53]}$. 后 来, 脱澳的光催化反应不需要紫罗碱, 只以乙腈为溶剂 在 $\left[\mathrm{Ru}(\mathrm{bpy})_{3}\right] \mathrm{Cl}_{2} / \mathrm{Et}_{3} \mathrm{~N}$ 下即可反应(Eq. 40) ${ }^{[54]}$. 关于该类 反应的机理, Teplý 在 2011 年的综述中做了详细介绍 ${ }^{[5]}$.
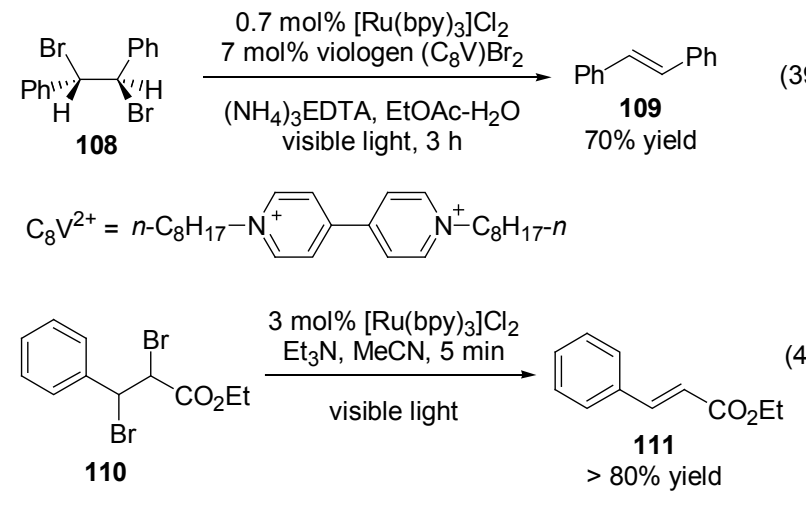

2011 年, Reiser 等 ${ }^{[55]}$ 报道了用光催化使邻二卤代物 的脱甾消除(Eq. 41). 该反应条件温和, 且收率高. 为 酮、酯和内酯等邻二直代物的脱卤提供了一条新的方法.

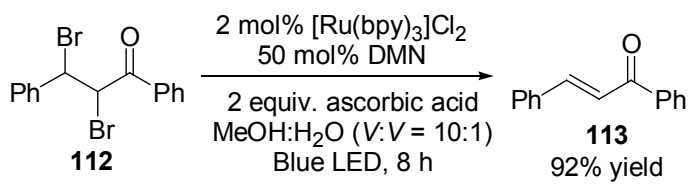

2011 年, Stephenson 等 ${ }^{[56]}$ 报道了利用光催化对醇的 溴化和碘化. 该反应有很好的官能团容忍性, 副产物少, 产率高且条件温和. 另外, 该反应操作简单, 具有一定 的工业价值(Eq. 42).

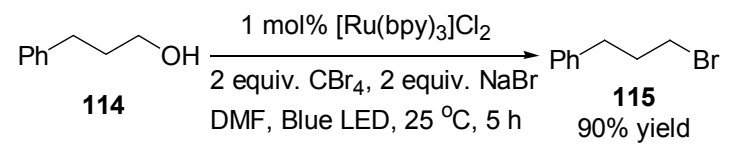

2011 年, Jiao 等 ${ }^{[57]}$ 报道了室温下 $\alpha$-芳基卤化物的衍 生物转变为 $\alpha$-芳基酮化合物(Eq. 43). 该反应在太阳光 照射、空气存在条件下, 利用光催化剂和有机催化剂共 同作用，高效的完成了这一新奇的转变.

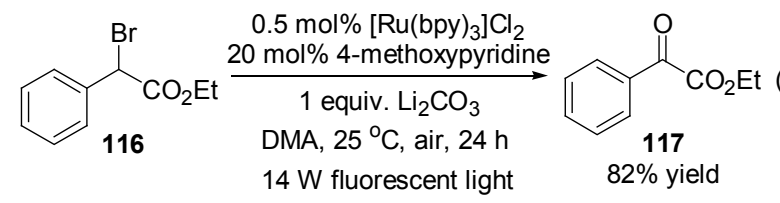

\section{4 涉及亚胺阳离子的反应}

\section{1 胺的 $\alpha$ 位取代反应}

2010 年, Stephenson 等 ${ }^{[58]}$ 报道了一种简单可行的氧 化偶联方法，通过光催化实现了硝基烷烃和芳基叔胺的 反应(Eq. 44). 该反应不需要其他的氧化剂, 只用了 1 $\mathrm{mol} \% \operatorname{Ir}(\mathrm{III})$ 催化剂, 在可见光照射下就得到了很高的产 率.

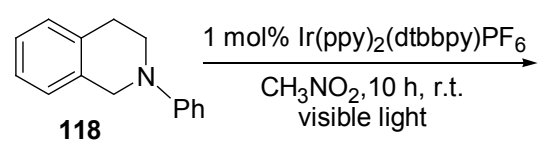

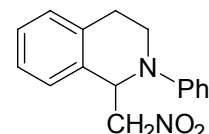

119 $92 \%$ yield
2011 年, Rueping 等 ${ }^{[59]}$ 报道了有光催化剂与 Lewis 碱共同作用的光催化 Mannich 反应(Eq. 45).

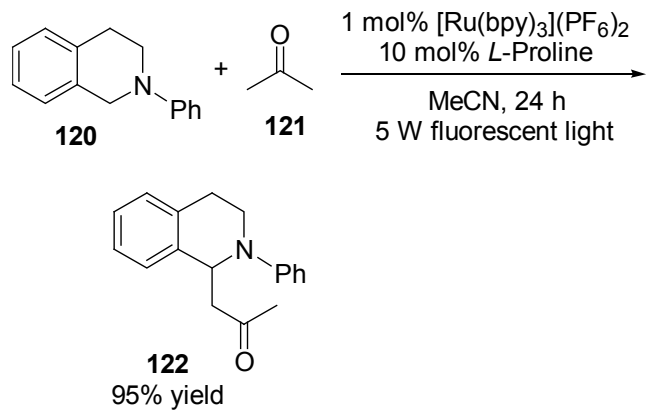

2011 年, Rueping 等 ${ }^{[60]}$ 报道了首例利用可见光催化 构建了 C-P 键(Eq. 46).

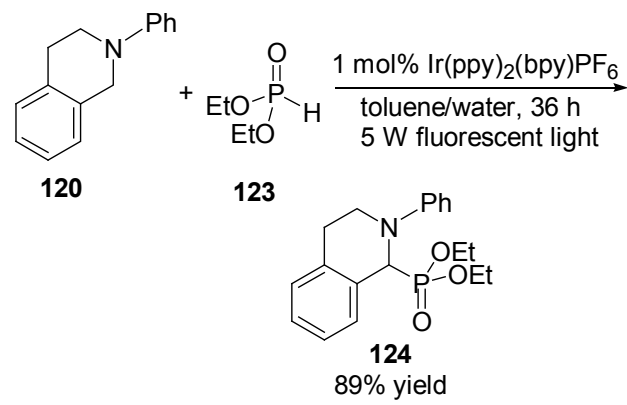

2011 年, König 等 ${ }^{[61]}$ 报道了用有机感光染料 eosin Y 实现了对叔胺 $\alpha$ 位几种取代反应. 该反应实现了无金属 催化的可见光氧化偶联(Scheme 7).

2011 年, Rueping 等 ${ }^{[62]}$ 报道了一种需氧的光催化氧 化新方法, 实现了对叔胺的 $\alpha$-氧化(Eq. 47). 该反应在温 和的条件下，用少量的催化剂得到很高的收率. 


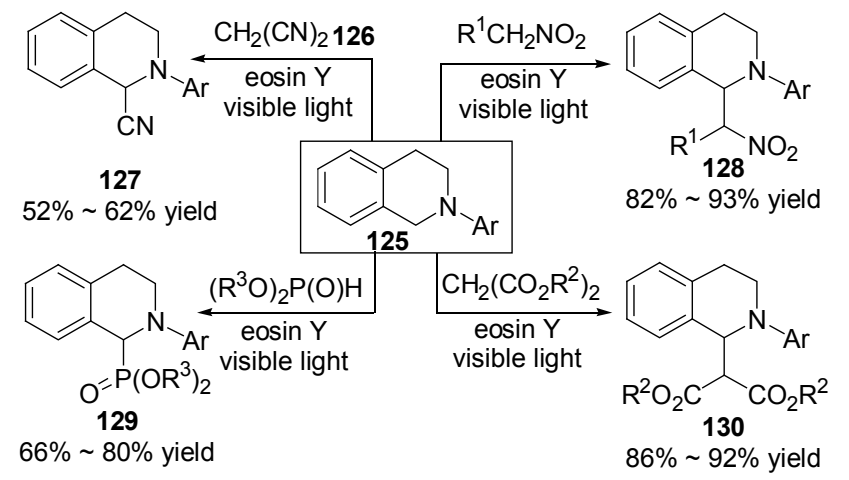

Scheme 7
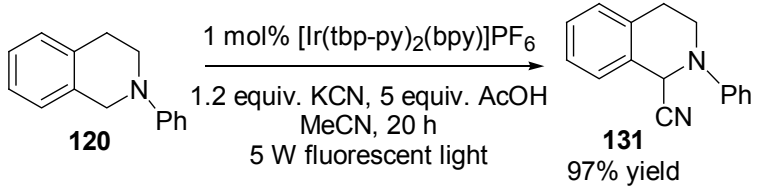

2012 年, Stephenson 等 ${ }^{[63]}$ 对该课题进行更深入研究, 拓宽了进攻亚胺阳离子中间体的亲核试剂的种类, 得到 了多种不同的产物. 并首次提出叔胺与烯丙基硅烷的反 应，得到不错的产率(Eq. 48).

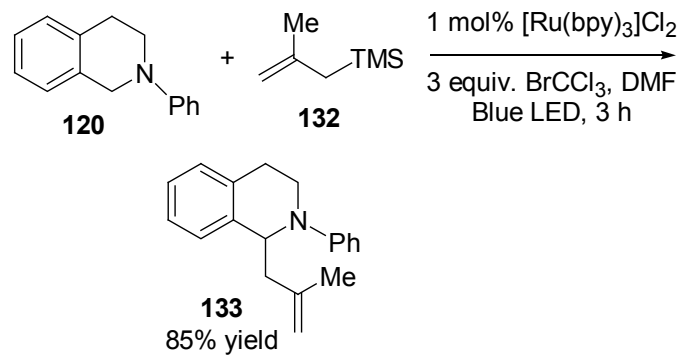

2012 年, Rueping 等 ${ }^{[64]}$ 报道了用金属氧化物代替原 来的铱和钉催化剂, 构建了 $\mathrm{C}-\mathrm{C}$ 键和 $\mathrm{C}-\mathrm{P}$ 键(Eq. 49).

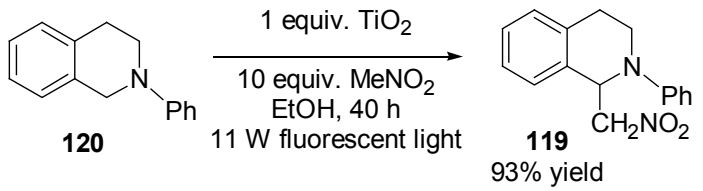

2012 年, Xia 等 ${ }^{[65]}$ 报道了在可见光催化下的叔胺与 烯醇硅烷反应(Eq. 50). 该反应用甲醇作溶剂, 蓝色的 $\mathrm{LED}$ 灯作为光源, $\mathrm{Ru}(\mathrm{bpy})_{3} \mathrm{Cl}_{2}$ 为光催化剂, 具有良好的 产率.
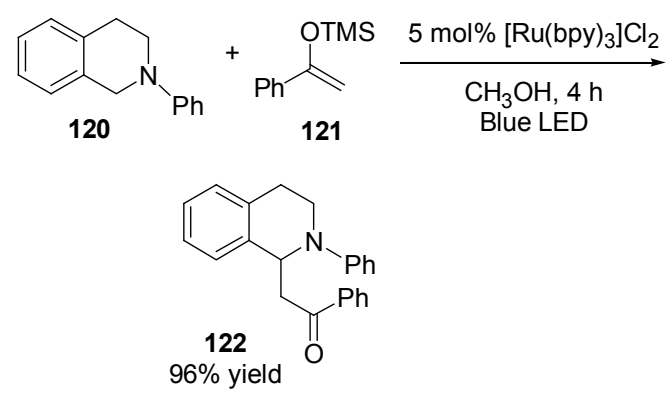

2012 年, Rueping 等 ${ }^{[66]}$ 报道了叔胺与炔烃的反应. 该反应采用了光催化和有机催化结合的双催化技术，并 且将底物叔胺从芳胺拓展到了脂肪胺(Eq. 51).

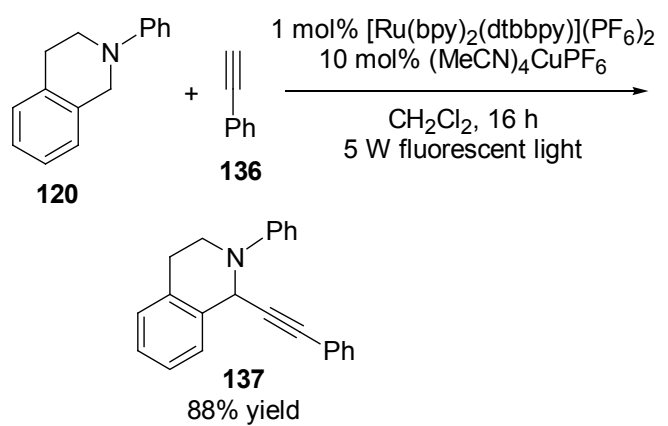

2011 年 Xiao 等 ${ }^{[67]}$ 利用光催化, 把二胺 138 通过分 子内环化合成了四氢咪唑类化合物 139. 并且该反应具 有很好的非对应选择性, 收率也很高. 这一发现为合成 四氢咪唑类化合物提供了一条高效的新途径(Eq. 52).

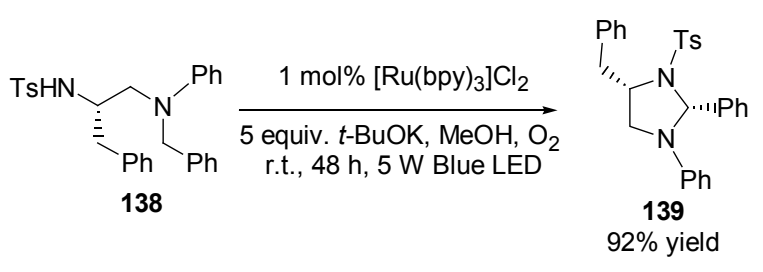

2012 年, Xiao 等 ${ }^{[68]}$ 报道了利用可见光催化巧妙的构 建了异喹啉 $[2,1-a][3,1]$ 悪嗪和异喹啉 $[2,1-\mathrm{a}]$ 嘧啶的骨架 (Eq. 53, 54). 光催化将成为合成重要生物杂环分子的一 种重要途径.
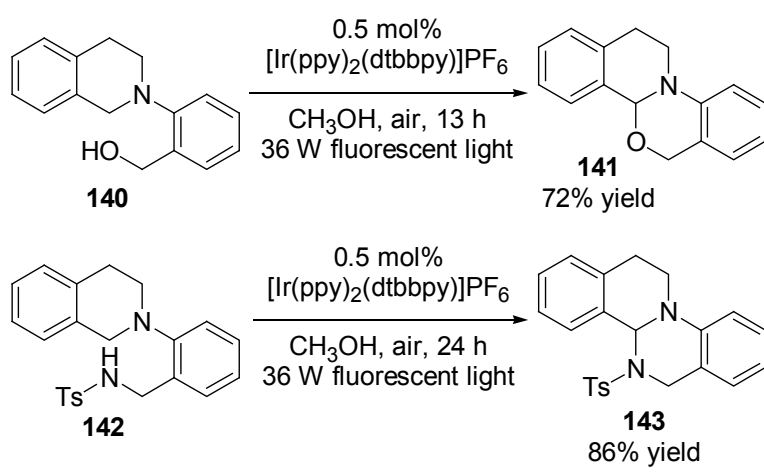

2012 年, Rovis 等 ${ }^{[69]}$ 报道了用双催化体系催化叔胺 的不对称 $\alpha$-酰基化(Eq. 55). 其中有机催化剂氮杂卡宾 使醛脱去质子形成羰基负离子，而光催化剂 $\mathrm{Ru}(\mathrm{bpy})_{3} \mathrm{Cl}_{2}$ 主要使叔胺转变为亚胺阳离子, 然后两者反应得到 $\alpha$-酰 基化产物

2012 年, Stephenson 等 ${ }^{[70]}$ 报道了酰胺烷基化的 Friedel-Crafts 反应(Eq. 56). 在室温下, 用 $\mathrm{Ru}(\mathrm{bpy})_{3} \mathrm{Cl}_{2}$ 为 光催化剂, 可见光和过硫酸盐存在下，二烷基酰胺先转 变为一个亚胺中间体，再由醇或富电子芳烃等亲核试剂 

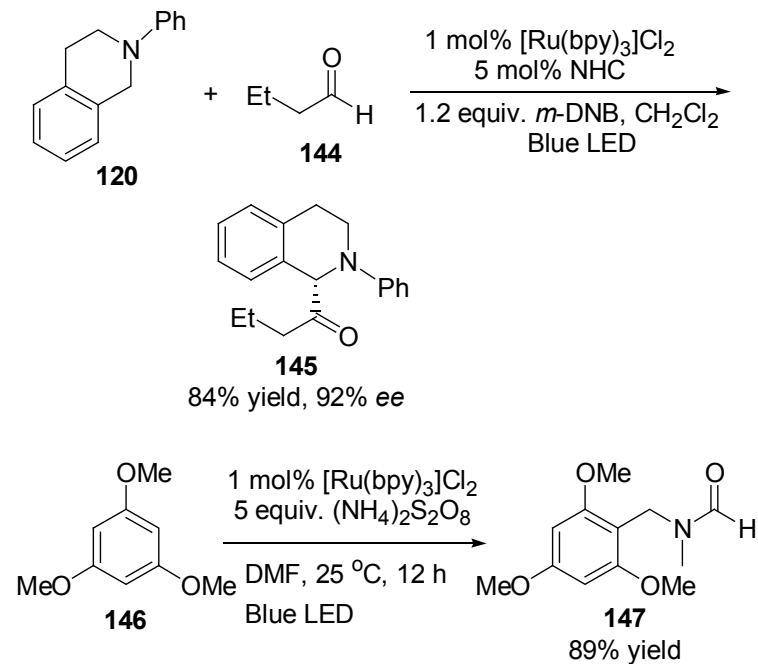

进攻, 可实现 $\mathrm{C}-\mathrm{O}$ 或 $\mathrm{C}-\mathrm{C}$ 键的形成. 而且, 光催化要 比热反应效果好, 能得到更高的收率和更好的选择性.

不久, $\mathrm{Li}$ 等 ${ }^{[71]}$ 受到 Stephenson 的报道的启发, 将这 一方法运用到 $\alpha$-氨基羰基化合物的 $\alpha$-芳基化(Eq. 57). 虽然该反应的产率还不是很高，但是这为 $\alpha$-氨基羰基化 合物杂环的引入提供了一种新的方法, 这对合成具有特 殊复合生物活性的 $\alpha$-氨基羰基化合物有重要意义.
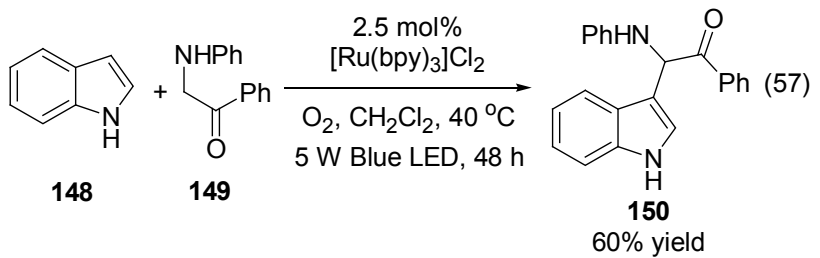

最近, Rueping 等 ${ }^{[72]}$ 报道了在可见光照射下铱催化 剂与 Lewis 酸协同催化 $\alpha$-氨基酸衍生物与吲哚类化合物

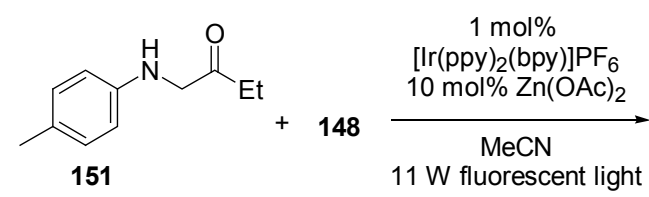<smiles></smiles>

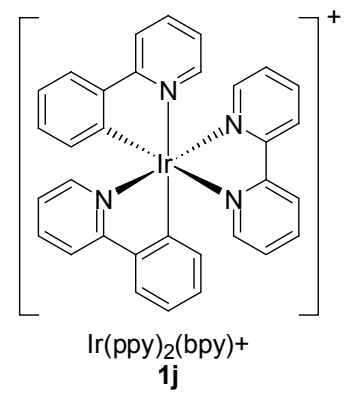

的反应(Eq. 58). 该研究实现了 $\alpha$-氨基酸衍生物及二肽 类化合物的官能团化.

2011 年, Tan 等 ${ }^{[73]}$ 报道了以二碘曙红为光催化剂, 石墨烯氧化物为氧化剂, 在绿光照射下完成叔胺的氧化 和三氟甲基化(Eq. 59).

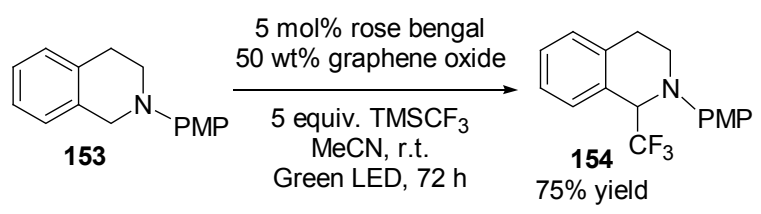

2012 年, $\mathrm{Fu}$ 等 ${ }^{[74]}$ 也报道了相似的结果, 但是用空气 代替了石墨烯作为氧化剂, 使反应更加方便(Eq. 60).

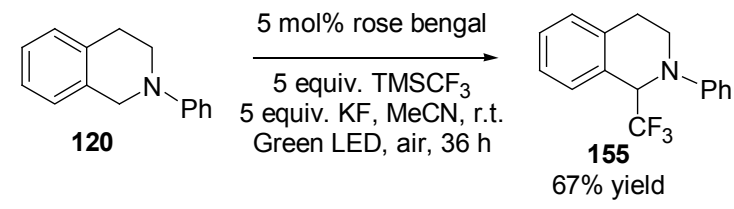

(60)

\section{$4.2[3+2]$ 偶极环加成}

2011 年 Xiao 等 ${ }^{[75]}$ 用光催化实现了一个串联反应, 研究得出其机理为氧化、 $[3+2]$ 环加成和芳构化的过程 (Eq. 61). 这一发现可以使合成具有生物活性的吡咯 [2,1-a]异喹啉变得快速高效, 所以这对合成一些天然产 物具有重要的应用意义.
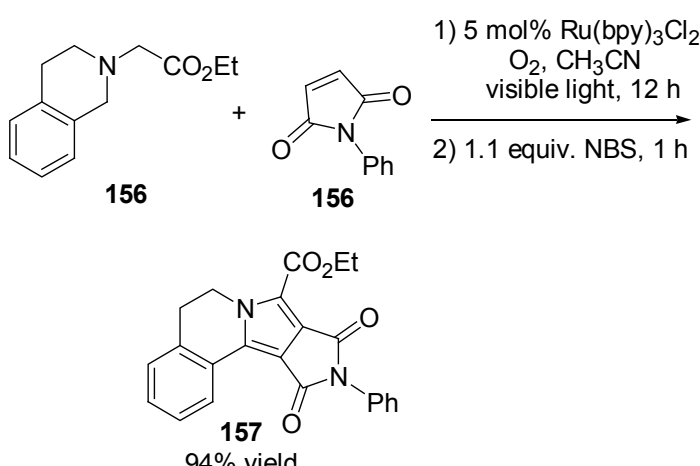

随后，Rueping 等 ${ }^{[76]}$ 也报道了关于[3+2]环加成(Eq. $62)$.

\section{3 其它的一些反应}

近年来, 多组分反应也越来越受到人们的关注, 其 步骤简单、高效的特点使其在有机合成中具有重要地位. 2011 年, Masson 等 ${ }^{[77]}$ 报道了一个三组分的酰胺 $\alpha$-烷基 化反应(Eq. 63). 该反应通过可见光催化，具有操作简 单、原子经济性高、底物范围广和产率高等特点, 可用 于对胺类化合物的修饰和改造.

2012 年, Son 等 ${ }^{[78]}$ 报道了在可见光照射下用有机染 料 165 催化伯胺氧化偶联反应(Eq. 64). 

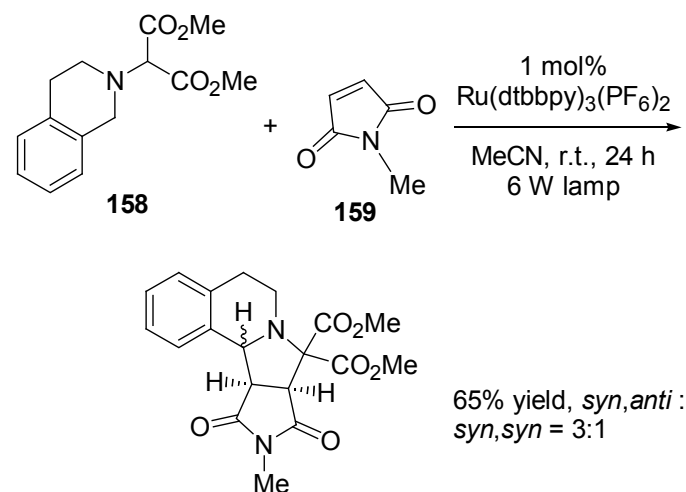

(62)

160

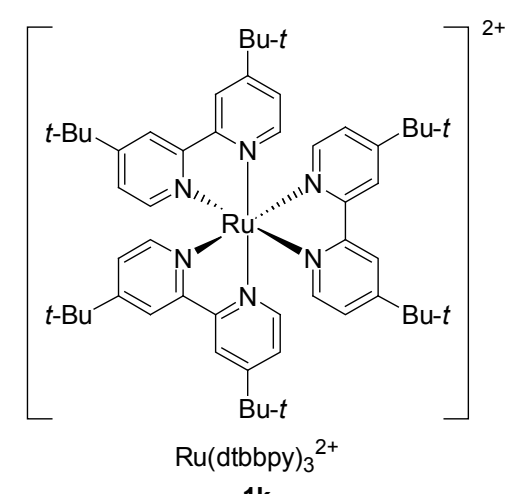

$1 \mathrm{k}$
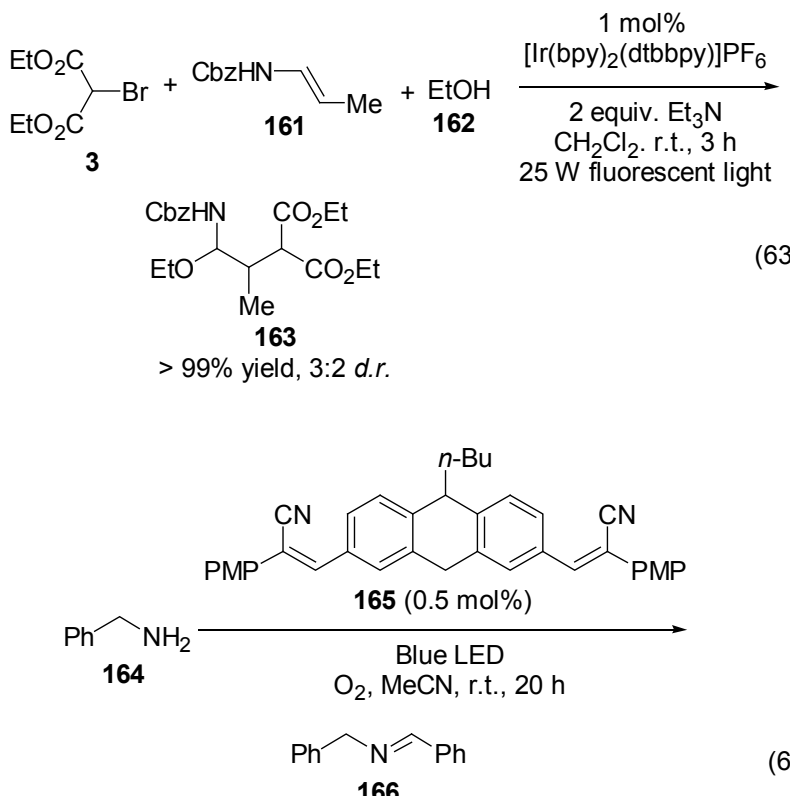

2012 年, Wang 等 ${ }^{[79]}$ 报道了光催化引起 $\mathrm{C}-\mathrm{C}$ 键断 裂，形成亚胺离子和胺自由基，然后再与其他物质反应 (Scheme 8). 这一研究突破了原有光催化在胺类物质中 对 C-H 键的活化, 丰富了反应形式.

2012 年, $\mathrm{Yu}$ 等 ${ }^{[80]}$ 报道了关于利用光催化对烯胺进 行烷基化(Eq. 65).

2012 年, Kobayashi 等 ${ }^{[81]}$ 报道了脂肪叔胺在可见光 催化下的有氧氧化(Eq. 66), 得到亚甲基桥联的 1,3-二 a) Iminium ion pathway

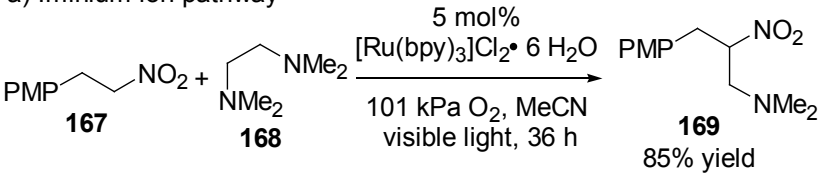

b) Amino radical pathway

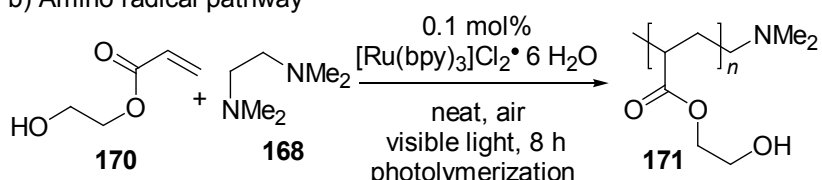

\section{Scheme 8}

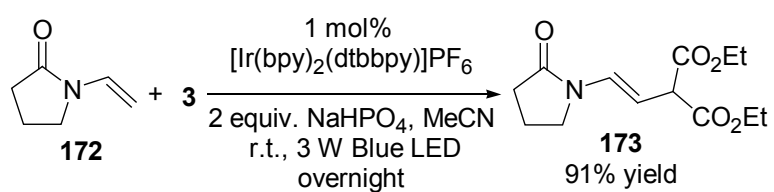

羰基化合物 $\mathbf{1 7 6}$.

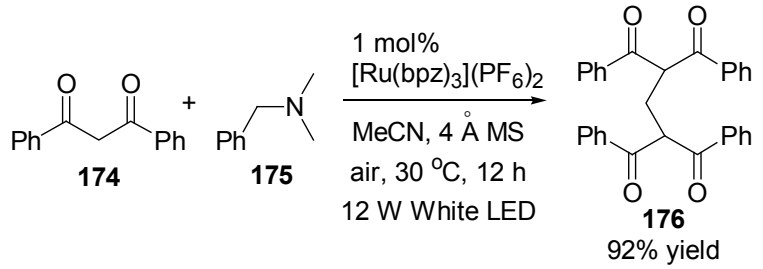

2012 年, Koike 和 Akita 等 ${ }^{[82]}$ 报道了在可见光催化下 的烯胺与烯醇硅烷的氧化偶联反应(Eq. 67). 该反应用 $\left[\mathrm{Ru}(\mathrm{bpy})_{3}\right]\left(\mathrm{PF}_{6}\right)_{2}$ 作催化剂, 苯醌类化合物为氧化剂(电 子受体), 而 $\mathrm{LiBF}_{4}$ 则为一种激活苯醌的 Lewis 酸, 加快 电子转移. 这一发现, 再一次把烯醇硅烷运用到有机合 成中，而且成功合成了 $\gamma$-二酮.

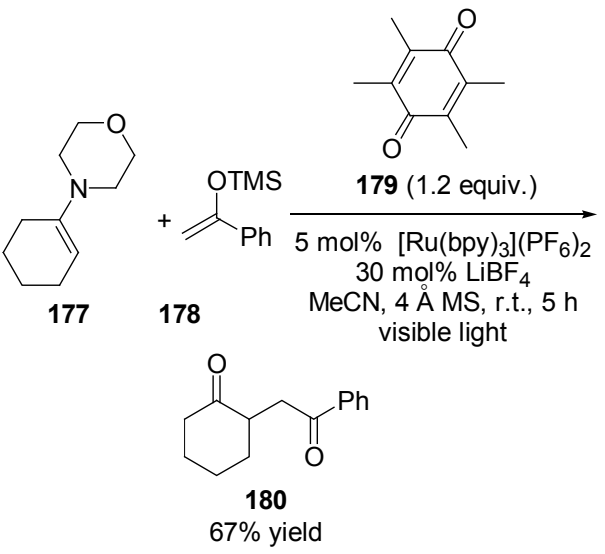

\section{$5 \alpha$-氨基碳自由基反应}

2011 年, MacMillan 等 ${ }^{[83]}$ 报道了叔胺的 $\alpha$-芳基化 (Eq. 68)

2012 年, Reiser 等 ${ }^{[84]}$ 报道了关于 $N$-芳基四氢喹啉衍 生物在光催化作用下形成 $\alpha$-氨基碳自由基，再与 $\alpha, \beta$-不 


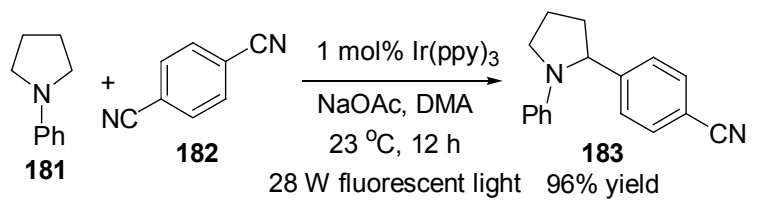

饱和酮发生 Michael 加成(Eq. 69).

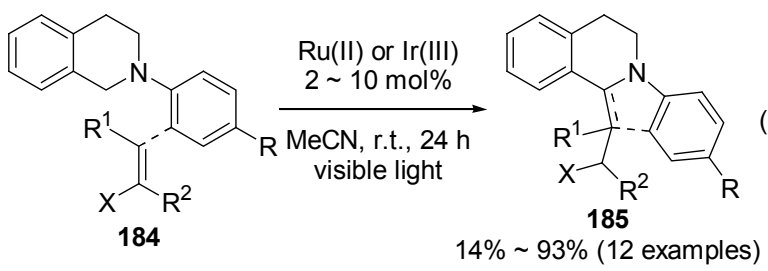

2012 年, Nishibayashi 等 $^{[85]}$ 报道了利用光催化完成 $\alpha$-氨基碳自由基与缺电子烯烃的加成(Eq. 70).

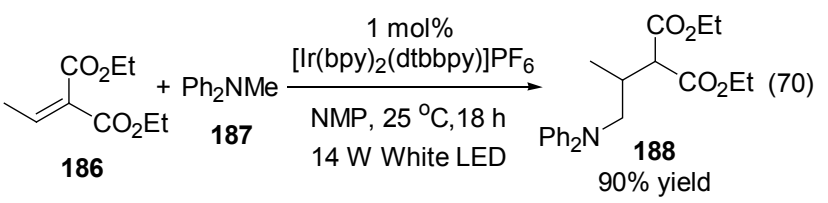

不久, 该课题组 ${ }^{[86]}$ 又报道了可见光催化下 $\alpha$-硅烷基 胺与 $\alpha, \beta$-不饱和酮的加成(Eq. 71). 胺 $\alpha$ 位的 $\mathrm{C}-\mathrm{H}$ 键活 化是合成含氮化合物的一种重要方法, 而该反应为之提 供了一种新的方法, 且 $\alpha$-硅烷基胺更易得到.

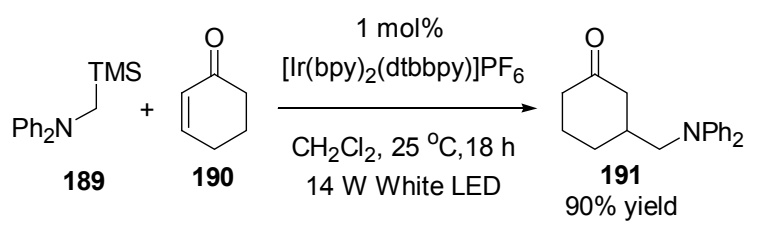

2012 年, Zheng 等 ${ }^{[87]}$ 报道了用可见光催化分子内苯 胺与烯烃反应环化合成 $N$-芳基吲哚, 也是一个构建 $\mathrm{C}$ $\mathrm{N}$ 键的一个例子(Eq. 72).

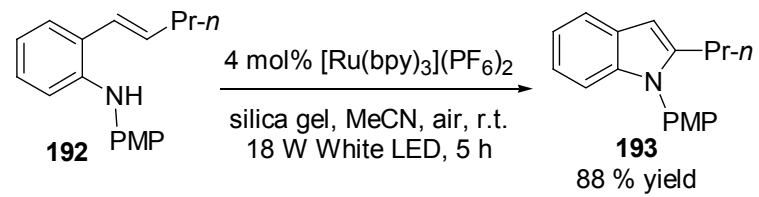

2102 年, $\mathrm{Yu}$ 等 ${ }^{[88]}$ 报道了在可见光催化下, 叔胺与马 来酰亚胺发生偶联合成四氢喹啉(Eq. 73). 该反应具有 催化效率高和操作简单等特点. 这也进一步证明了 $\alpha$-氨

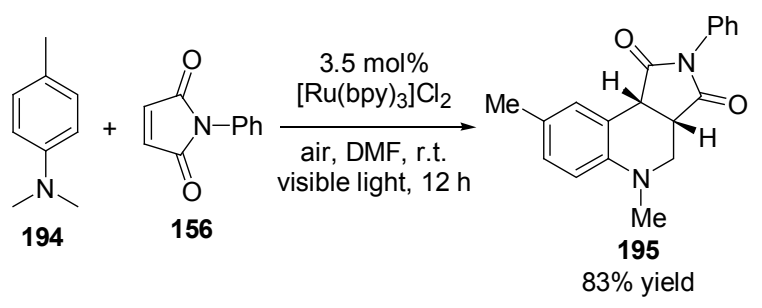

基烷基自由基在有机合成中的重要价值.

2012 年, Nishibayashi 等 ${ }^{[89]}$ 报道了利用光催化对苯 并含氮杂环的胺化(Eq. 74).

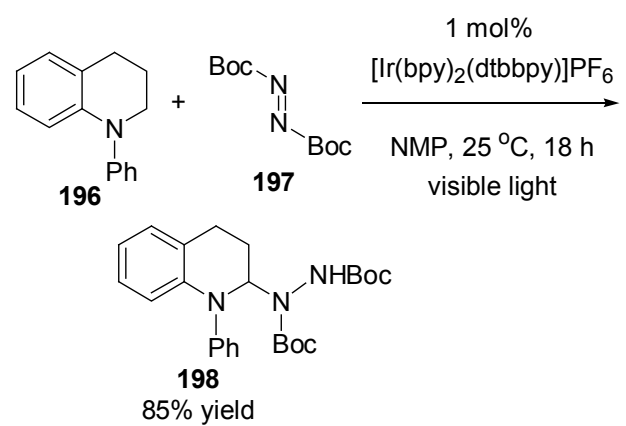

2013 年, Rueping 等 ${ }^{[90]}$ 报道了可见光催化的分子间 及分子内胺与烯烃的自由基加成与环化(Eqs. 75 77). 当有氧气参与时, 反应主要生成环化产物; 否则以加成 产物为主.

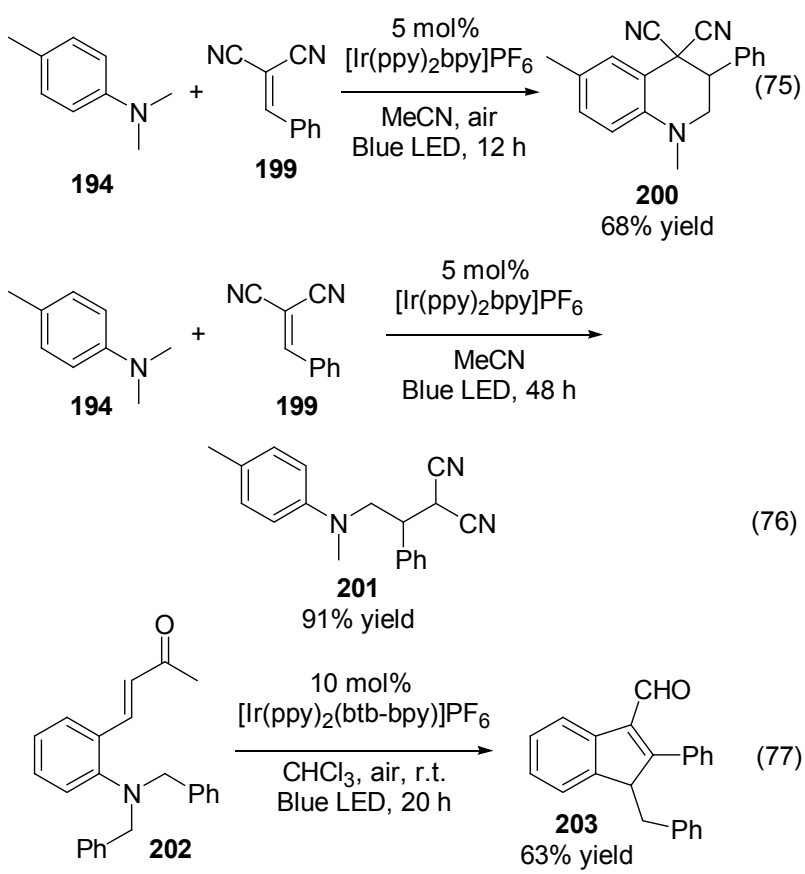

\section{6 重氮盐参与的反应}

在 1984 年, Cano-Yelo 和 Deronzier 等 ${ }^{[91]}$ 报道了用芳 基重氮盐合成菲的衍生物，且基本上能得到定量的产物 (Scheme 9) ${ }^{[5]}$. 在该反应中, 光催化剂具有非常重要的作 用. 当不加光催化剂而直接光照时，反应产物为混合物 且偶联产物的产率非常低(Scheme 10) $)^{[5]}$.

2012 年, König 等 ${ }^{[92]}$ 报道了关于用重氮盐对杂环芳 香化合物的芳基化(Eq. 78). 该反应在可见光照射下，用 有机染料 eosin Y 做光催化剂，条件温和，操作简单，而 且克服了 Meerwein 芳基化的缺点, 在有机合成中具有 更广的应用性. 


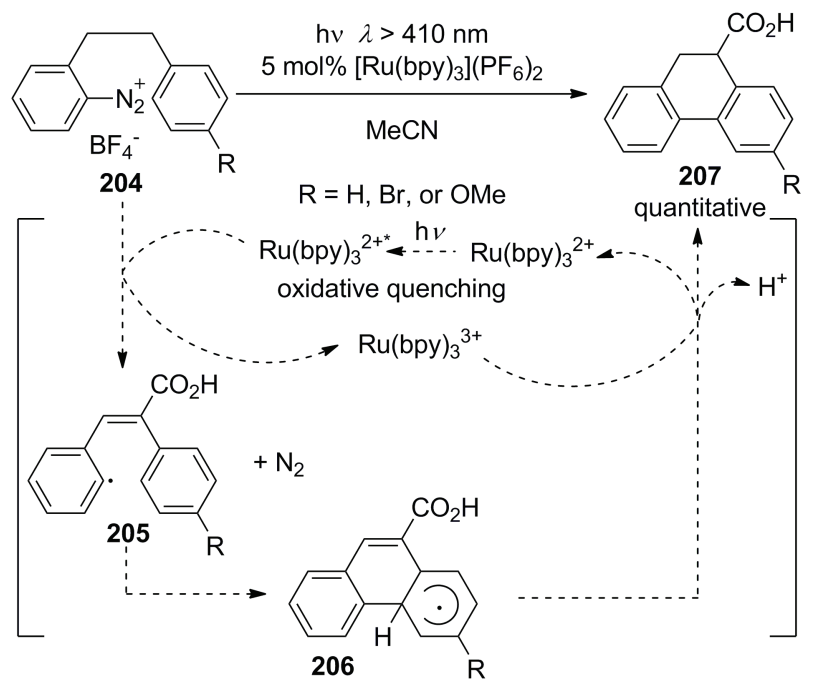

Scheme 9

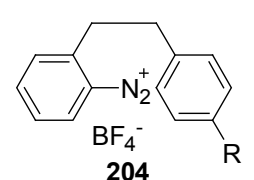

$\mathrm{R}=\mathrm{H}, \mathrm{Br}$, or OMe

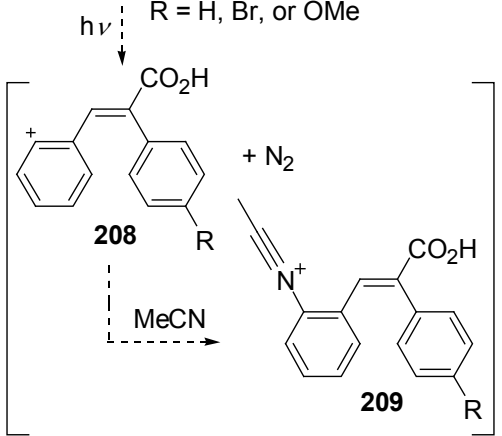

Scheme 10

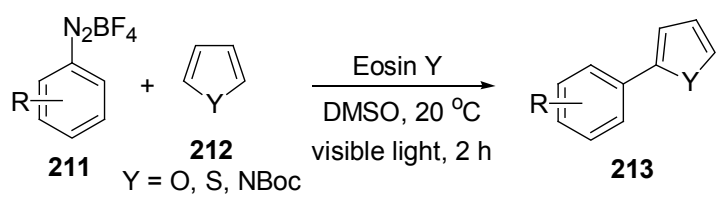

随后, König 等 ${ }^{[93]}$ 又将底物拓展到烯烃、炔烃和烯 酮，完成了它们的芳基化(Eq. 79). 其中使用光催化剂 $\left[\mathrm{Ru}(\mathrm{bpy})_{3}\right]^{2+}$ 代替了原先的染料 $\operatorname{eosin} \mathrm{Y}$, 得到了更好的 催化效果.

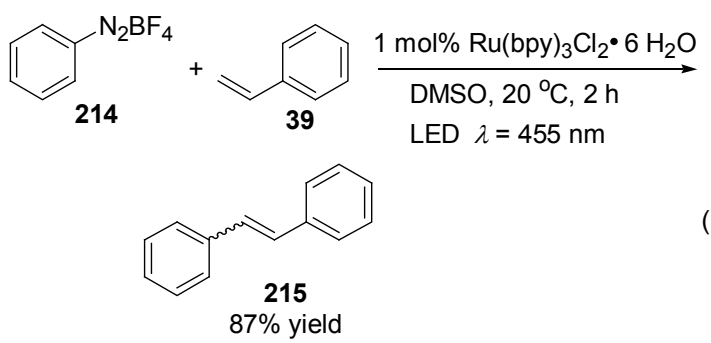

之后，König 等 ${ }^{[94]}$ 又报道了一种合成苯并噻吩的新 方法. 该方法在绿光照射下，有机染料 eosin Y 作光催化 剂. 利用重氮盐与炔烃的反应巧妙的合成了苯并噻吩 (Eq. 80).

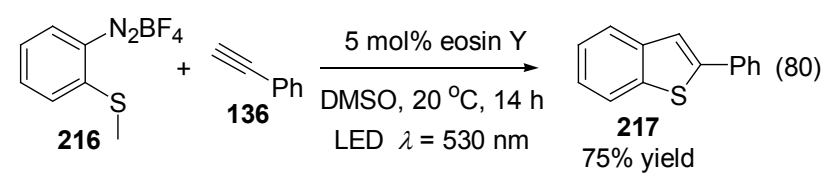

最近，König 等 ${ }^{[95]}$ 又报道了关于利用重氮盐对烯醇 乙酸酯的芳基化. 利用这一反应，可以进一步合成 2-取 代的吲哚类化合物(Scheme 11).

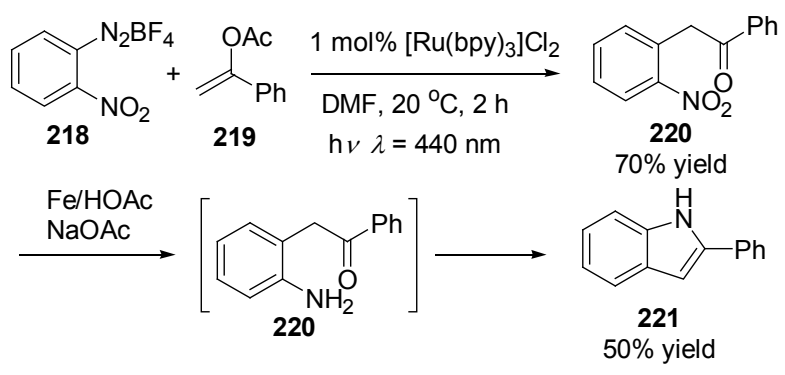

Scheme 11

\section{7 含硫化合物的反应}

2012 年, Stephenson 等 ${ }^{[49]}$ 报道了利用光催化实现对 甲苯磺酰氯 222 与烯烃的加成(Eq. 81). 报道中给出的烯 烃种类不多，该方法的普遍性有待提高. 但是这一发现 丰富了对甲苯磺酸在合成中的应用.

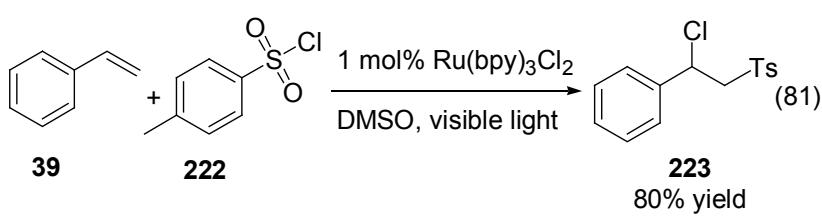

2012 年, Zheng 等 ${ }^{[96]}$ 报道了用芳基磺酰氯 222 和 $N$ 甲基吲哚 81 的还原偶联反应(Eq. 82).

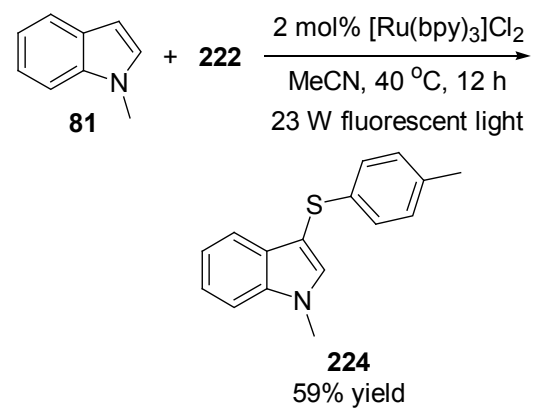

2012 年, 在氧气的存在下, $\mathrm{Li}$ 等 ${ }^{[97]}$ 报道了一种取代 的 $N$-苯基硫代甲酰胺的分子内环化得到 2-取代的苯并 噻唑的光催化反应(Eq. 83). 


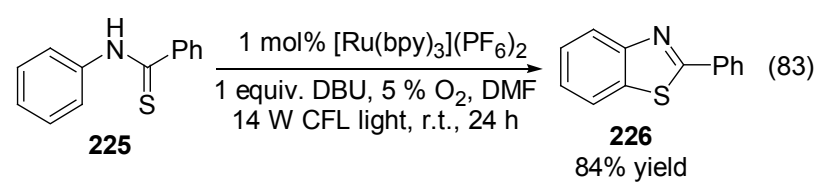

2013 年, Yoon 等 ${ }^{[98]}$ 报道了在蓝光照射下用 $\mathrm{Ru}(\mathrm{bpz})_{3}\left(\mathrm{PF}_{6}\right)_{2}$ 作催化剂的硫醇与烯烃的反应. 该反应有 很高的产率, 而且通用性很好, 适用于多种硫醇和烯烃 反应(Eq. 84$)$.

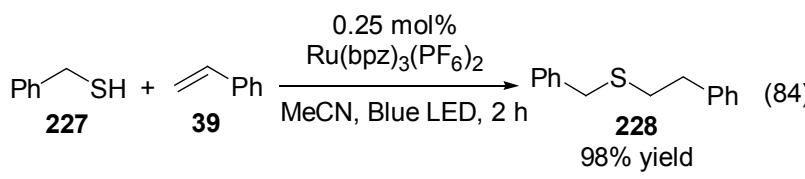

\section{8 官能团的脱保护}

2009 年, Falvey 等 ${ }^{[99]}$ 报道了以 $\mathrm{Ru}(\mathrm{bpy})_{3} \mathrm{Cl}_{2}$ 为光催化 剂、以 $\mathrm{H}_{2} \mathrm{Asc}$ 为还原剂和质子供体在光催化作用下, 酯 分解释放出酸. 利用该方法可在合成中实现羧酸的保护 (Eq. 85).
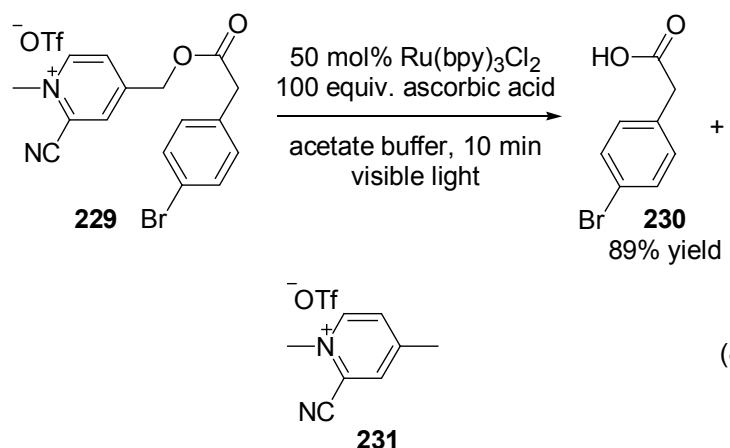

2011 年, Boncella 等 ${ }^{[100]}$ 报道了氨基甲酸酯在光催化 作用下分解释放出伯胺(Eq. 86). 该反应以 $\mathrm{Ru}(\mathrm{bpy})_{3} \mathrm{Cl}_{2}$ 为光催化剂, $\mathrm{H}_{2} \mathrm{Asc}$ 为还原剂和质子供体, 反应条件温 和、产率高. 伯胺可以先经一步简单反应生成对应氨基 甲酸酯, 这样氨基就被保护起来, 可以避免氨基对其他 反应的干扰. 待其他反应结束后, 再经该光催化反应将 氨基释放出来. 这一发现为有机合成中氨基的保护提供

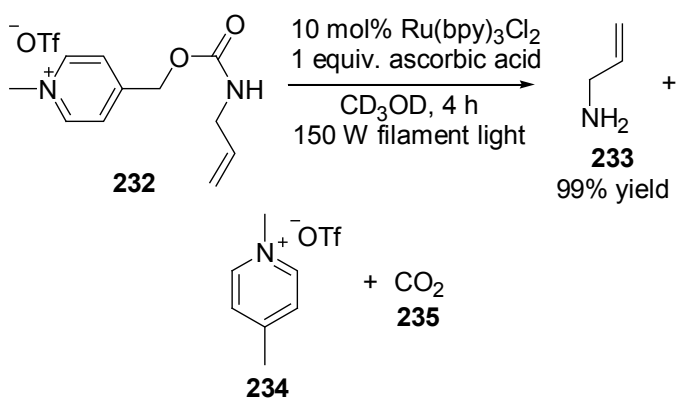

了一种新的方法. 该方法有望运用于生物化学中氨基核 苷酸的保护。

\section{9 三元环开环反应}

2006 年，Hasegawa 等 ${ }^{[101]}$ 报道了利用感光试剂 BDMAP 或 $\mathrm{Ru}(\mathrm{bpy})_{3} \mathrm{Cl}_{2}$ 作催化剂，二甲基苯并咪唑作还 原剂, 在光照条件下完成了 $\alpha$-环氧酮类化合物的还原开 环(Eqs. 87, 88).

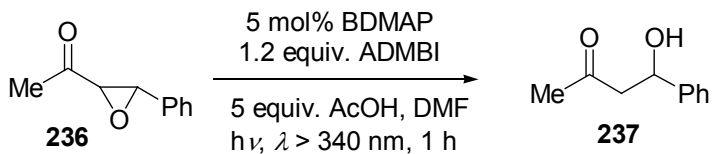

$64 \%$ conv., $80 \%$ yield
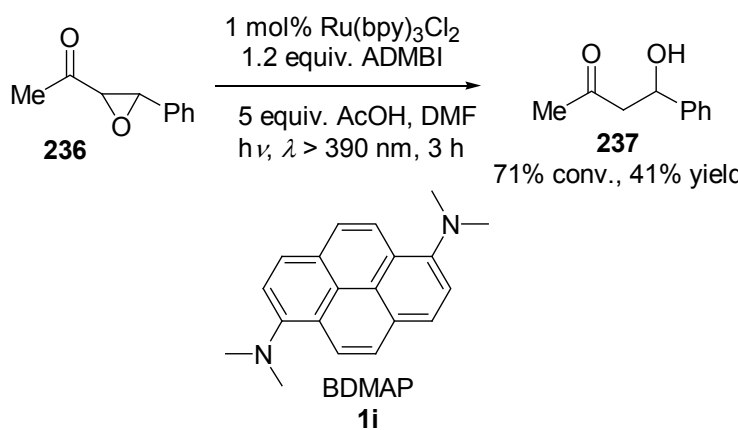

2011, Ollivier 等 ${ }^{[102]}$ 报道了利用可见光催化对环氧 化物和环氮化物进行开环还原反应以及与烯烃的反应 (Eqs. 89, 90).
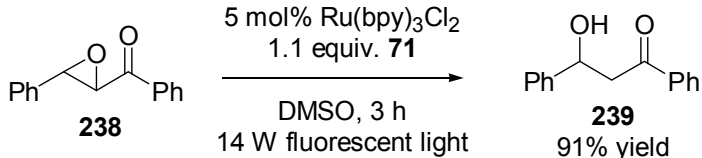

$238+$

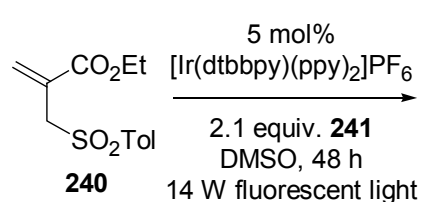<smiles>C=C(CC(C(=O)Oc1ccccc1)C(O)c1ccccc1)C(=O)OCC</smiles><smiles>CCOC(=O)C1=C(C)NC(C)=C(C(=O)OCC)C1</smiles><smiles>[Z14][Z14]1(C)NC(C)=C(C(=O)OCC)C(C)C1C(=O)OCC</smiles>

\section{0 芳烃及烯烃的三氟甲基化}

2011 年, MacMillan 等 ${ }^{[103]}$ 报道了利用光催化完成了 三氟甲基磺酰氯与芳环和杂环化合物的三氟甲基化反 应(Eq. 91).

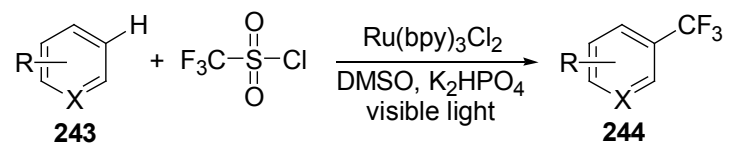


2012 年, Cho 等 ${ }^{[104]}$ 也报道了对杂环芳烃的三氟甲基 化. 该反应用 $\mathrm{CF}_{3} \mathrm{I}$ 作三氟甲基化试剂, $\mathrm{Ru}(\mathrm{bpy})_{3} \mathrm{Cl}_{2}$ 作光 催化剂, 加入碱 TMEDA, 在可见光照射下能得到很好 的收率(Eq. 92).

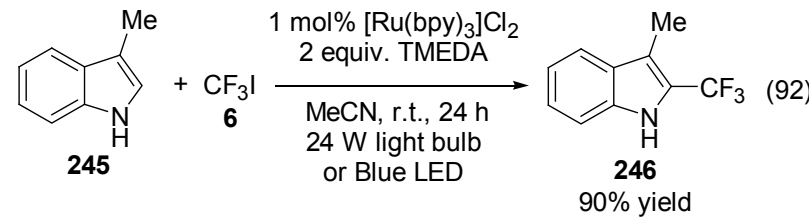

$\mathrm{Ye}$ 和 Sanford ${ }^{[105]}$ 报道了用光催化剂 $\mathrm{Ru}(\mathrm{bpy})_{3} \mathrm{Cl}_{2}$ 和 $\mathrm{CuOAc}$ 的联合催化下完成芳基硼酸的三氟甲基化(Eq. 93).

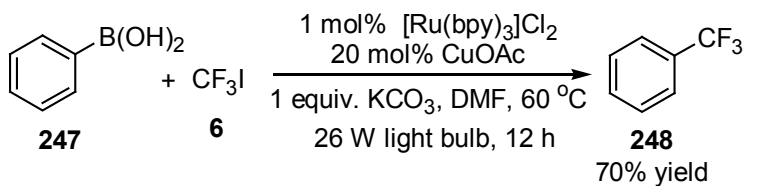

2013 年, Koike 和 Akita 等 ${ }^{[106]}$ 报道了乙烯基嗍酸盐 的三氟甲基化(Eq. 94).

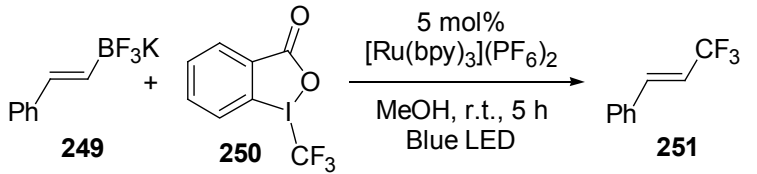

\section{1 其它的氧化反应}

2011 年, $\mathrm{Wu}$ 等 ${ }^{[107]}$ 报道了在光照条件下用铼催化剂 使 3,4-二氢嘧啶酮氧化为嘧啶酮(Eq. 95).

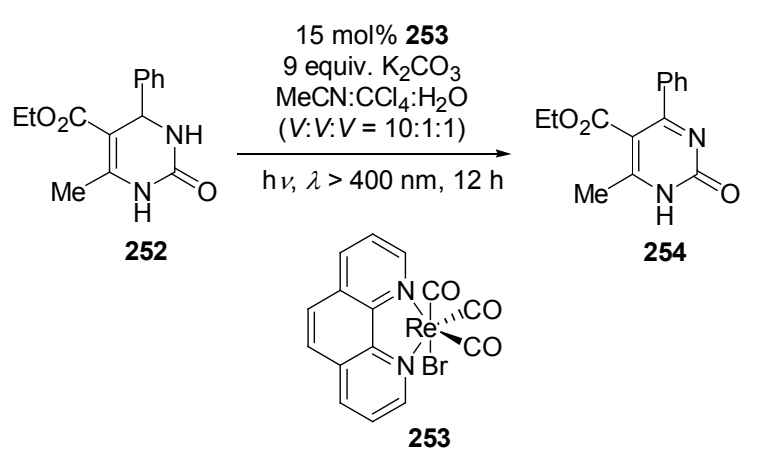

2012 年, Xiao 等 ${ }^{[108]}$ 报道了用空气作氧化剂的光催 化反应，实现了芳基硼酸的有氧氧化差基化得到苯酚类 化合物(Eq. 96).

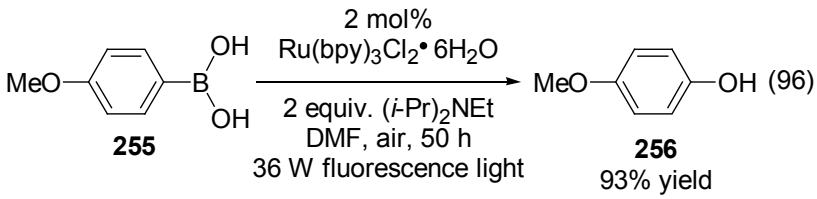

2013 年, Xia 等 ${ }^{[109]}$ 报道了可见光催化的醛类化合物 的 $\mathrm{C}-\mathrm{C}$ 键断裂. 该反应以 $\mathrm{Ru}(\mathrm{bpy})_{3} \mathrm{Cl}_{2}$ 为光催化剂, 空 气作氧化剂, 在室温下反应就能得到很好的收率. 此外, 他们还将这一方法运用于串联的 Michael 加成和 $\mathrm{C}-\mathrm{C}$ 键断裂成环反应(Eqs. 97, 98).
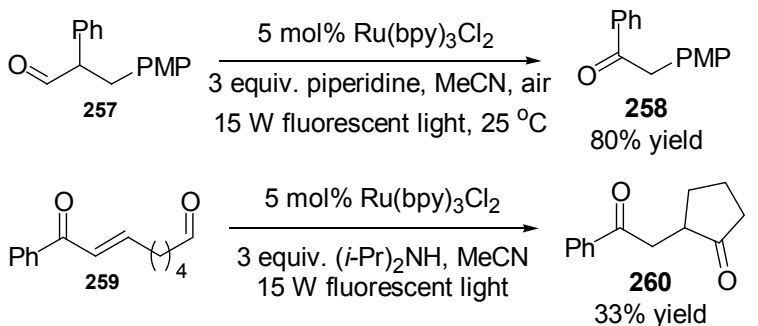

\section{2 其它的还原反应}

2004 年, Hirao 等 ${ }^{[10]}$ 报道了利用可见光催化, 用催 化量的 $\left[\mathrm{Ru}(\mathrm{bpy})_{2}(\mathrm{MeCN})_{2}\right]\left(\mathrm{PF}_{6}\right)_{2}$ 作光催化剂, 并加入化 学当量的水合肼作还原剂, 把硝基苯还原成苯胺. 2011 年, Ananthakrishnan 等 ${ }^{[111]}$ 用有机染料 eosin Y 作光催化 剂同样得到了硝基苯的还原，并具有良好的产率(Eq. 99).

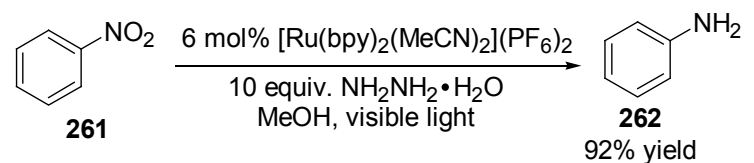

另外, 在 2011 年, Liu 等 ${ }^{[112]}$ 报道了利用可见光催化 将叠氮化合物还原为胺(Eq. 100).

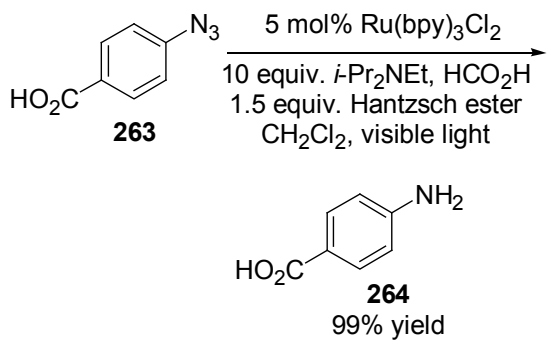

2012 年, Xia 等 ${ }^{[113]}$ 报道了在可见光照射下查尔酮的 还原偶联环化. 研究发现 $\operatorname{Sm}(\mathrm{OTf})_{3}$ 作 Lewis 酸效果最好 (Eq. 101).

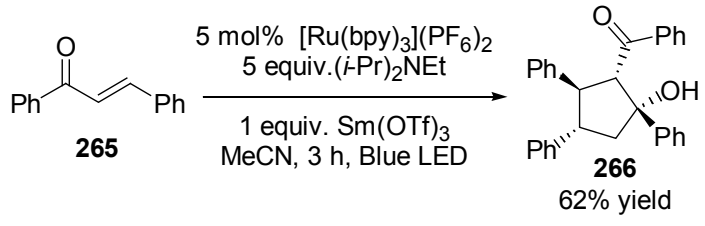




\section{3 结论与展望}

综上所述，可见光催化已经成为有机合成中一种强 大而高效的手段, 不仅在一些简单反应中可行, 而且可 以运用于合成一些有生物活性的复杂分子. 此外, 微流 光催化的发展使得连续生产成为可能 ${ }^{[14 \sim 118]}$. 毫无疑 问, 可见光催化将会引领我们发现更多更有用的反应. 但是它还面临着一些问题和挑战需要解决. 一些反应的 催化机理没有确切的解释、寻找更高效稳定廉价的催化 剂及催化剂的回收这些都是可见光催化领域里接下来 需要继续研究的.

\section{References}

[1] Ciamician, G. Science 1912, 36, 385.

[2] Zeitler, K. Angew. Chem., Int. Ed. 2009, 48, 9785.

[3] Yoon, T. P.; Ischay, M. A.; Du, J. Nat. Chem. 2010, 2, 527.

[4] Narayanam, J. M. R.; Stephenson, C. R. J. Chem. Soc. Rev. 2011, 40, 102.

[5] Teplý, F. Collect. Czech. Chem. Commun. 2011, 76, 859.

[6] Shi, L.; Xia, W. J. Chem. Soc. Rev. 2012, 41, 7687.

[7] You, Y.; Nam, W. Chem. Soc. Rev. 2012, 41, 7061.

[8] Xuan, J.; Xiao, W. J. Angew. Chem., Int. Ed. 2012, 51, 6828.

[9] Xi, Y. M.; Yi, H.; Lei, A. W. Org. Biomol. Chem. 2013, 11, 2387.

[10] Prier, C. K.; Rankic, D. A.; MacMillan, D. W. C. Chem. Rev. 2013, $113,5322$.

[11] Nicewicz, D. A.; MacMillan, D. W. C. Science 2008, 322, 77.

[12] Nagib, D. A.; Scott, M. E.; MacMillan, D. W. C. J. Am. Chem. Soc. 2009, 131, 10875.

[13] Shih, H. W.; Vander Wal, M. N.; Grange, R. L.; MacMillan, D. W. C. J. Am. Chem. Soc. 2010, 132, 13600.

[14] Neumann, M.; Füldner, S.; König, B.; Zeitler, K. Angew. Chem., Int. Ed. 2011, 50, 951

[15] Pham, P. V.; Nagib, D. A.; MacMillan, D. W. C. Angew. Chem., Int. Ed. 2011, 50, 6119 .

[16] Cherevatskaya, M.; Neumann, M.; Füldner, S.; Harlander, C.; Kümmel, S,; Dankesreiter, S.; Pfitzner, A.; Zeitler, K.; König, B. Angew. Chem., Int. Ed. 2012, 51, 4062.

[17] Koike, T.; Akita, M. Chem. Lett. 2009, 38, 166.

[18] Ischay, M. A.; Anzovino, M. E.; Du, J.; Yoon, T. P. J. Am. Chem. Soc. 2008, 130, 12886.

[19] Du, J.; Yoon, T. P. J. Am. Chem. Soc. 2009, 131, 14604.

[20] Ischay, M. A.; Lu, X.; Yoon, T. P. J. Am. Chem. Soc. 2010, 132, 8572.

[21] Du, J.; Espelt, L. R.; Guzei, I. A.; Yoon, T. P. Chem. Sci. 2011, 2, 2115.

[22] Hurtley, A .E.; Cismesia, M. A.; Ischay, M. A.; Yoon, T. P. Tetrahedron 2011, 67, 4442.

[23] Lu, Z.; Shen, M.; Yoon, T. P. J. Am. Chem. Soc. 2011, 133, 1162.

[24] Maity, S.; Zhu, M.; Shinabery R. S.; Zheng, N. Angew. Chem., Int. Ed. 2012, 51, 222.

[25] Lin, S. S.; Ischay, M. A.; Fry, C. G.; Yoon, T. P. J. Am. Chem. Soc. 2011, 133, 19350.

[26] Tyson, E. L.; Farney, E. P.; Yoon, T. P. Org. Lett. 2012, 14, 1110.

[27] Parrish, J. D.; Ischay, M. A.; Lu, Z.; Guo, S.; Peters, N. R.; Yoon, T. P. Org. Lett. 2012, 14, 1640.

[28] Lin, S. S.; Padilla, C. E.; Ischay, M. A.; Yoon, T. P. Tetrahedron Lett. 2012, 53, 3073.

[29] Zou, Y. Q.; Duan, S. W.; Meng, X. G.; Hu, X. Q.; Gao, S.; Chena,
J. R.; Xiao, W. J. Tetrahedron 2012, 68, 6914.

[30] Ischay, M. A.; Ament, M. S.; Yoon, T. P. Chem. Sci. 2012, 3, 2807.

[31] Lu, Z.; Yoon, T. P. Angew. Chem. 2012, 124, 10475.

[32] Deng, G. B. Wang, Z. Q.; Xia, J. D.; Qian, P. C.; Song, R. J.; Hu, M.; Gong, L. B.; Li, J. H. Angew. Chem., Int. Ed. 2013, 52, 1535.

[33] Mashraqui, S. H.; Kellogg, R. M. Tetrahedron Lett. 1985, $26,1453$.

[34] Fukuzumi, S.; Mochizuki, S.; Tanaka T. J. Phys. Chem. 1990, 94, 722.

[35] Narayanam, J. M. R.; Tucker, J. W.; Stephenson, C. R. J. J. Am. Chem. Soc. 2009, 131, 8756.

[36] Andrews, R. S.; Becker, J. J.; Gagné, M. R. Org. Lett. 2011, 13, 2046.

[37] Nguyen, J. D.; D’Amato, E. M.; Narayanam, J. M. R.; Stephenson, C. R. J. Nat. Chem. 2012, 4, 854.

[38] Tucker, J. W.; Narayanam, J. M. R.; Krabbe, S. W.; Stephenson, C. R. J. Org. Lett. 2010, 12, 368.

[39] Tucker, J. W.; Nguyen, J. D.; Narayanam, J. M. R.; Krabbe, S. W.; Stephenson, C. R. J. Chem. Commun. 2010, 46, 4985.

[40] Furst, L.; Matsuura, B. S.; Narayanam, J. M. R.; Tucker, J. W.; Stephenson, C. R. J. Org. Lett. 2010, 12, 3104.

[41] Furst, L.; Narayanam, J. M. R.; Stephenson, C. R. J. Angew. Chem, Int. Ed. 2011, 50, 9655.

[42] Andrews, R. S.; Becker, J. J.; Gagné, M. R. Angew. Chem., Int. Ed. 2010, 49, 7274.

[43] Tucker, J. W.; Stephenson, C. R. J. Org. Lett. 2011, 13, 5468.

[44] Ju, X. H.; Liang, Y.; Jia, P. J.; Li, W. F.; Yu, W. Org. Biomol. Chem. 2012, 10, 498.

[45] Kim, H.; Lee, C. Angew. Chem., Int. Ed. 2012, 51, 12303.

[46] Liu, Q.; Yi, H.; Liu, J.; Yang, Y. H.; Zhang, X.; Zeng, Z. Q.; Lei. A. W. Chem. Eur. J. 2013, 19, 5120.

[47] Nguyen, J. D.; Tucker, J. W.; Konieczynska, M, D.; Stephenson, C. R. J. J. Am. Chem. Soc. 2011, 133, 4160.

[48] Pirtsch, M.; Paria, S.; Matsuno, T.; Isobe, H.; Reiser, O. Chem. Eur. J. 2012, 18, 7336.

[49] Wallentin, C. J.; Nguyen, J. D.; Finkbeiner, P.; Stephenson, C. R. J. J. Am. Chem. Soc. 2012, 134, 8875.

[50] Maidan, R.; Goren, Z.; Becker, J. Y.; Willner, I. J. Am. Chem. Soc. 1984, 106, 6217.

[51] Goren, Z.; Willner, I. J. Am. Chem. Soc. 1983, 105, 7764.

[52] Maidan, R.; Willner, I. J. Am. Chem. Soc. 1986, 107, 1080.

[53] Mandler, D.; Willner, I. J. Am. Chem. Soc. 1984, 106, 5352.

[54] Willner, I.; Tsfania, T.; Eichen, Y. J. Org. Chem. 1990, 55, 2656.

[55] Maji, Tapan.; Karmakar, Ananta.; Reiser, Oliver. J. Org. Chem. 2011, 76, 736.

[56] Dai, C. H.; Narayanam, J. M. R.; Stephenson, C. R. J. Nat. Chem. 2011, 3, 140.

[57] Su, Y. J.; Zhang, L. R.; Jiao, N. Org. Lett. 2011, 13, 2168.

[58] Condie, A. G.; González-Gómez, J. C.; Stephenson, C. R. J. J. Am. Chem. Soc. 2010, 132, 1464.

[59] Rueping, M.; Vila, C.; Koenigs, R. M.; Poscharny K.; Fabry, D. C. Chem. Commun. 2011, 47, 2360.

[60] Rueping, M.; Zhu S. Q.; Koenigs, R. M. Chem. Commun. 2011, 47, 8679.

[61] Hari, D. P.; König, B. Org. Lett. 2011, 13, 3852.

[62] Rueping, M.; Zhu, S. Q.; Koenigs, R. M. Chem. Commun. 2011, 47, 12709.

[63] Freeman, D. B.; Furst, L.; Condie, A. G.; Stephenson, C. R. J. Org. Lett. 2012, 14, 94.

[64] Rueping, M.; Zoller, J.; Fabry, D. C.; Poscharny, K.; Koenigs, R. M.; Weirich, T. E.; Mayer, J. Chem. Eur. J. 2012, 18, 3478.

[65] Zhao, G. L.; Yang, C.; Guo, L.; Sun, H.; Chen, C.; Xia, W. J. Chem. Commun. 2012, 48, 2337. 
[66] Rueping, M.; Koenigs, R. M.; Poscharny, K.; Fabry, D. C.; Leonori, D.; Vila, C. Chem. Eur. J. 2012, 18, 5170.

[67] Xuan, J.; Cheng, Y.; An, J.; Lu, L. Q.; Zhang, X. X.; Xiao, W. J. Chem. Commun. 2011, 47, 8337.

[68] Xuan, J.; Feng, Z. J.; Duan, S. W.; Xiao, W. J. RSC Adv. 2012, 2, 4065 .

[69] DiRocco, D. A.; Rovis, T. J. Am. Chem. Soc. 2012, 134, 8094.

[70] Dai, C. H.; Meschini, F.; Narayanam, J. M. R.; Stephenson, C. R. J. J. Org. Chem. 2012, 77, 4425.

[71] Wang, Z. Q.; Hu, M.; Huang, X. C.; Gong, L. B. Xie, Y. X.; Li, J. H. J. Org. Chem. 2012, 77, 8705.

[72] Zhu, S. Q.; Rueping, M. Chem. Commun. 2012, 48, 11960.

[73] Pan, Y. H.; Wang, S. A.; Kee, C. W.; Dubuisson, E.; Yang, Y. Y.; Loh, K. P.; Tan. C. H. Green Chem. 2011, 13, 3341.

[74] Fu, W. J.; Guo, W. B.; Zou, G. L.; Xu, C. J. Fluorine Chem. 2012, $140,88$.

[75] Zou, Y. Q.; Lu, L. Q.; Fu, L.; Chang, N. J.; Rong, J.; Chen, J. R.; Xiao, W. J. Angew. Chem., Int. Ed. 2011, 50, 7171.

[76] Rueping, M.; Leonori, D.; Poisson, T. Chem. Commun. 2011, 47, 9615.

[77] Courant, T.; Masson, G. Chem. Eur. J. 2012, 18, 423.

[78] Park, J. H.; Ko, K. C.; Kim, E.; Park, N.; Ko, J. H.; Ryu, D. H.; Ahn, T. K.; Lee, J. Y.; Son, S. U. Org. Lett. 2012, 14, 5502.

[79] Cai, S. Y.; Zhao, X. Y.; Wang, X. B.; Liu, Q. S.; Li, Z. G.; Wang, D. Z. Angew. Chem. 2012, 124, 8174.

[80] Jiang, H.; Huang, C. M.; Guo, J. J.; Zeng, C. Q.; Zhang, Y.; Yu, S. Y. Chem. Eur. J. 2012, 18, 15158.

[81] Yoo, W.-J.; Tanoue, A.; Kobayashi, S. Chem. Asian J. 2012, 7, 2764.

[82] Yasu, Y.; Koike, T.; Akita, M. Chem. Commun. 2012, 48, 5355.

[83] McNally, A.; Prier, C. K.; MacMillan, D. W. C. Science 2011, 334, 1114.

[84] Kohls, P.; Jadhav, D.; Pandey, G.; Reiser, O. Org. Lett. 2012, 14, 672.

[85] Miyake, Y.; Nakajima, K.; Nishibayashi, Y. J. Am. Chem. Soc. 2012, 134, 3338.

[86] Miyake, Y.; Ashida, Y.; Nakajima, K.; Nishibayashi, Y. Chem. Commun. 2012, 48, 6966.

[87] Maity, S.; Zheng, N. Angew. Chem., Int. Ed. 2012, 51, 9562.

[88] Ju, X. H.; Li, D. J.; Li, W. F.; Yu, W.; Bian, F. L. Adv. Synth. Catal. 2012, 354, 3561 .

[89] Miyake, Y.; Nakajima, K.; Nishibayashi, Y. Chem. Eur. J. 2012, $18,16473$.

[90] Zhu, S. Q.; Das, A.; Bui, L.; Zhou, H. J.; Curran, D. P.; Rueping, M. J. Am. Chem. Soc. 2013, 135, 1823.

[91] Cano-Yelo, H.; Deronzier A. J. Chem. Soc., Perkin Trans. 2 1984,
1093.

[92] Hari, D. P.; Schroll, P.; König, B. J. Am. Chem. Soc. 2012, 134, 2958.

[93] Schroll, P.; Hari, D. P.; König, B. ChemistryOpen 2012, 1, 130.

[94] Hari, D. P.; Hering, T.; König, B. Org. Lett. 2012, 14, 5334.

[95] Hering, T.; Hari, D. P.; König, B. J. Org. Chem. 2012, 77, 10347.

[96] Chen, M.; Huang, Z. T.; Zheng, Q. Y. Chem. Commun. 2012, 48, 11686.

[97] Cheng, Y. N.; Yang, J.; Qu, Y.; Li, P. Org. Lett. 2012, 14, 98.

[98] Tyson, E. L.; Ament, M. S.; Yoon, T. P. J. Org. Chem. 2013, 78, 2046.

[99] Borak, J. B.; Falvey, D. E. J. Org. Chem. 2009, 74, 3894.

[100] Edson, J. B.; Spencer, L. P.; Boncella, J. M. Org. Lett. 2011, 13, 6156.

[101] Hasegawa, E.; Takizawa, S.; Seida, T.; Yamaguchi, A.; Yamaguchi, N.; Chiba, N.; Takahashi, T.; Ikeda, H.; Akiyama, K. Tetrahedron 2006, 62, 6581.

[102] Larraufie, M. H.; Pellet, R.; Fensterbank, L.; Goddard, J. P.; Lacôte, E.; Malacria, M.; Ollivier, C. Angew. Chem. 2011, 123, 4555.

[103] Nagib, D. A.; MacMillan, D. W. C. Nature 2011, 480, 224.

[104] Iqbal, N.; Choi, S.; Ko, E.; Cho, E. J. Tetrahedron Lett. 2012, 53, 2005.

[105] Ye, Y.; Sanford, M. S. J. Am. Chem. Soc. 2012, 134, 9034.

[106] Yasu, Y.; Koike, T.; Akita, M. Chem. Commun. 2013, 49, 2037.

[107] Liu, Q.; Li, Y. N.; Zhang, H. H.; Chen, B.; Tung, C. H.; Wu, L. Z. J. Org. Chem. 2011, 76, 1444.

[108] Zou, Y. Q.; Chen, J. R.; Liu, X. P.; Lu, L. Q.; Davis, R. L.; Jørgensen, K. A.; Xiao, W. J. Angew. Chem., Int. Ed. 2012, 51, 784.

[109] Sun, H. N.; Yang, C.; Gao, F.; Li, Z.; Xia, W. J. Org. Lett. 2013, 15, 624.

[110] Hirao, T.; Shiori, J.; Okahata, N. Bull. Chem. Soc. Jpn. 2004, 77, 1763.

[111] Gazi, S.; Ananthakrishnan, R. Appl. Catal. B 2011, 105, 317.

[112] Chen, Y. Y.; Kamlet, A. S.; Steinman, J. B.; Liu, D. R. Nat. Chem. 2011, 3, 146 .

[113] Zhao, G. L.; Yang, C.; Guo, L.; Sun, H. N.; Lin, R.; Xia, W. J. J. Org. Chem. 2012, 77, 6302.

[114] Andrews, R. S.; Becker, J. J.; Gagné, M. R. Angew. Chem., Int. Ed. 2012, 51, 4140 .

[115] Bou-Hamdan, F. R.; Seeberger, P. H. Chem. Sci. 2012, 3, 1612.

[116] Tucker, J. W.; Zhang, Y.; Jamison, T. F.; Stephenson, C. R. J. Angew. Chem., Int. Ed. 2012, 51, 4144.

[117] Nguyen, J. D.; Reiß, B.; Dai, C. H.; Stephenson, C. R. J. Chem. Commun. 2013, 49, 4352.

[118] Neumann, M. Zeitler, K.; Org. Lett. 2012, 14, 2658. 